\title{
Ion-Imprinted Electrochemical Sensor Based on Copper Nanoparticles-Polyaniline Matrix for Nitrate Detection
}

\author{
Houda Essousi $\mathbb{D}^{1},{ }^{1}$ Houcine Barhoumi $\left(\mathbb{D},{ }^{1}\right.$ Malek Bibani, ${ }^{2,3}$ Nadia Ktari, ${ }^{2}$ \\ Frank Wendler, ${ }^{4}$ Ammar Al-Hamry, ${ }^{4}$ and Olfa Kanoun ${ }^{4}$ \\ ${ }^{1}$ Laboratory of Interfaces and Advanced Materials, University of Monastir, Faculty of Sciences of Monastir, 5000 Monastir, Tunisia \\ ${ }^{2}$ Laboratoire Matériaux, Traitement et Analyse, INRAP, Biotechpole Sidi-Thabet, 2020, Ariana, Tunisia \\ ${ }^{3}$ Université de Tunis El Manar, Faculté des Sciences de Tunis, Campus Universitaire Farhat Hached, 1068 Tunis, Tunisia \\ ${ }^{4}$ Chair for Measurement and Sensor Technology, Technische Universitat Chemnitz, Reichenhainer Str. 70, 09126 Chemnitz, Germany
}

Correspondence should be addressed to Houcine Barhoumi; houcine.barhoumi@fsm.rnu.tn

Received 21 November 2018; Accepted 18 April 2019; Published 15 May 2019

Academic Editor: Harith Ahmad

Copyright (C) 2019 Houda Essousi et al. This is an open access article distributed under the Creative Commons Attribution License, which permits unrestricted use, distribution, and reproduction in any medium, provided the original work is properly cited.

\begin{abstract}
This study reports a new chemical sensor based on ion-imprinted polymer matrix using copper nanoparticles-polyaniline nanocomposite (IIP-Cu-NPs/PANI). This sensor was prepared by electropolymerization using aniline as a functional monomer and nitrate as template onto the copper nanoparticles-modified glassy carbon (GC) electrode surface. Both ion-imprinted (IIP) and nonimprinted (NIP) electrochemical sensor surfaces were evaluated using UV-Visible spectrometry and scanning electron microscopy (SEM). The electrochemical analysis was made via cyclic voltammetry (CV), linear sweep voltammetry (LSV), and impedance spectroscopy (IS). Throughout this study various analytical parameters, such as scan rate, $\mathrm{pH}$ value, concentration of monomer and template, and electropolymerization cycles, were optimized. Under the optimum conditions, the peaks current of nitrate was linear to its concentration in the range of $1 \mu \mathrm{M}-0.1 \mathrm{M}$ with a detection limit of $31 \mu \mathrm{M}$ and $5 \mu \mathrm{M}$ by EIS and LSV. The developed imprinted nitrate sensor was successfully applied for nitrate determination in different real water samples with acceptable recovery rates.
\end{abstract}

\section{Introduction}

Nitrate is recognized as a significant contaminant in ground water because of its high environmental and human health risks. It is mostly present in aquatic ecosystems and food products [1-3]. The Environmental Protection Agency (EPA) recommended maximum limit for nitrate concentration in drinking water is $10 \mathrm{mg} . \mathrm{L}^{-1}[4,5]$. The negatively charged nitrogen oxide compound $\mathrm{NO}_{3}{ }^{-}$can accelerate the growth of algae and, thus, causes lakes and rivers eutrophication. Several studies revealed that the presence of higher levels of nitrate in drinking water leads to harmful diseases such as methemoglobinemia [6-8], gastrointestinal tumors [9], and stomach cancer [10-12]. Moreover, nitrate can be readily reduced to nitrites and ammonia, even more toxic, by microbial reduction in food products [13]. These compounds can also cause a large decrease in oxygen carrying capacity of hemoglobin, which may lead to death. Generally, the levels of nitrate are measured with analytical techniques such as ultraviolet (UV) spectrometry $[14,15]$, ion chromatography [16, 17], Raman spectroscopy [18], chemiluminescence [19], and electrochemical techniques [20-22], but most of these methods have few disadvantages, related to high instruments cost, low reproducibility, and time consuming [23]. Therefore, it is needful to establish an easy, rapid, and credible method to detect nitrate in water. For emphasizing these matters, Molecular Imprinting technique has induced a considerable research interest thanks to its good manageability, innocuous nature, high selectivity, low cost, high stability, and quick response $[24,25]$. This technique is based on a complex formation between a template molecule and monomer(s) and, then, the use of this template as an artificial receptor to produce cavities which are able to recognize only the same template molecule of interest. The same strategy is obedient to the selective recognition of ions. [26, 27]. Up to now, surface ion imprinting technique has found interesting 
applications in sensors, membrane separation of imprint metal ions, and solid-phase extractions [28, 29]. Over the last few years, various materials involving conductive polymers, carbon nanotube metal, metal oxide nanoparticles, and graphene have been explored for the modification of the electrode aiming at increasing the sensitivity and selectivity of the imprinted electrochemical sensor. Among the materials used for the electroreduction of nitrate, polyaniline (PANI) is one of the most conducting polymers in the field of electrochemical sensing. PANI is considered as metal nanoparticles stabilizer and a good electrocatalyst due to its high chemical stability, high conductivity, low cost, and environmental stability [30-32]. It has been demonstrated that copper nanosheets on $\mathrm{WO}_{3} / \mathrm{PANI}$ composite can be used to detect the reduction of nitrate with a good sensitivity and low detection limit [33]. In comparison with conventional methods, electrochemical deposition is simple, convenient, and reproducible for the deposition of IIP film on the surface of the electrode. Similarly, as far as the electrochemical reduction of nitrate is concerned, metal nanoparticles such as palladium [34], rhodium [35], copper [36], platinum [37], and silver $[38,39]$ can not only offer marked improvements in sensitivity and selectivity but also be manufactured easily and reproducibly. Therefore, this kind of catalyst has been widely studied and used in electrochemical sensors for nitrate detection. Copper nanoparticles have been vastly used in electrode modification thanks to their extraordinary catalytic activities, good electrical properties, biocompatibility, large specific surface area, and high conductivity [40, 41]. Indeed, many chemically modified coppers metal nanoparticles in non-IIP films have recently been reported for the detection of nitrate ions in different environments. Some researchers have demonstrated that copper nanoparticles electrochemically deposited on platinum electrode are useful in the detection of nitrate ions. In this work, we report a novel, rapid, and highly sensitive ion-imprinted electrochemical sensor based on copper nanoparticles and polyaniline (Cu-NPs/PANI) nanocomposites for the determination of nitrate ions. The electrochemical behavior of the deposit matrix on the electrode surface was investigated by cyclic voltammetry, electrochemical impedance spectroscopy, and linear sweep voltammetry. The proposed sensor exhibits good analytical performances such as sensitivity, selectivity, and high binding affinity toward nitrate determination.

\section{Materials and Methods}

2.1. Chemicals. Aniline, $\mathrm{H}_{2} \mathrm{SO}_{4}, \mathrm{NaOH}, \mathrm{HCl}, \mathrm{K}_{2} \mathrm{HPO}_{4}$, $\mathrm{CuSO}_{4} \cdot 5 \mathrm{H}_{2} \mathrm{O}, \mathrm{Na}_{2} \mathrm{SO}_{4}$, sodium nitrate $\left(\mathrm{NaNO}_{3}\right)$, sodium nitrite $\left(\mathrm{NaNO}_{2}\right), \mathrm{NaCl}, \mathrm{Mg}^{2}$, and $\mathrm{CO}_{3}{ }^{2-}$ were all obtained from Sigma-Aldrich. Ferricyanide $\left(\mathrm{K}_{4}\left(\mathrm{Fe}(\mathrm{CN})_{6}\right)\right.$ and ferrocyanide $\left(\mathrm{K}_{3}\left(\mathrm{Fe}(\mathrm{CN})_{6}\right)\right.$ were obtained from Fluka. All chemicals used in this work were of analytical grade and used as received without further purification.

2.2. The Preparation of Ion-Imprinted Electrodes toward Nitrate Ions. Cyclic voltammetry and linear sweep voltammetry were performed using a potentiostat (DY200 POT
Ecochimie) and an Autolab PGSTAT 320N potentiostat for electrochemical impedance measurements controlled by a computer using commercially available Nova version 1,5 software. The UV-Visible absorbance spectra were recorded in 67 series spectrophotometers models 6705 UV/Vis JENWAY ON indium-tin oxide (ITO) glass $(10 \mathrm{ohm} / \mathrm{mm})$ as working electrode to study UV-Visible spectral behavior. A typical three-electrode system was chosen to perform electrochemical measurements; a rotating glassy carbon electrode disk $\left(\mathrm{GCE}_{\mathrm{s}}\right)$ was used as a working electrode, $\mathrm{Ag} / \mathrm{AgCl} / 3 \mathrm{M} \mathrm{KCl}$ electrode as a reference electrode, and a Pt wire as a counter electrode.

2.3. Modification of the Working Electrode. Before the modification of the working electrode, it was hand-polished with 1 and $0.05 \mu \mathrm{m}$ alumina-water slurry using a polishing cloth, washed, and then sonicated in acetone for $5 \mathrm{~min}$ to remove adsorbed particles. To ensure a clean surface, the bare GC disk electrode was rinsed with ultrapure water and subjected to $0.5 \mathrm{M}$ sodium hydroxide by cycling the potential between 0.2 and $1.4 \mathrm{~V}$ until a stable cyclic voltammogram was obtained. The cleaned electrode was dried in air before use. The modification process consists in electrodepositing a fresh copper layer using the chronoamperometry method, onto the GCE surface by applying a potential step of $-0.2 \mathrm{~V}$ for $120 \mathrm{~s}$ in $0.1 \mathrm{M}$ of $\mathrm{Na}_{2} \mathrm{SO}_{4}$ solution. After depositing the copper layer on the GCE, it was rinsed with deionized water and allowed to dry in air. After deoxygenating the solution by bubbling nitrogen gas for about $10 \mathrm{~min}$, the IIP was prepared by electropolymerization of $0.1 \mathrm{M}$ of aniline in $0.5 \mathrm{M} \mathrm{H}_{2} \mathrm{SO}_{4}$ solution as supporting electrolyte in presence of $1 \mathrm{mM}$ of sodium nitrate as template onto the Cu-NPs/GCE, through cyclic voltammetry by applying 10 successive polymerization cycles from $-0.2 \mathrm{~V}$ to $1 \mathrm{~V}$ with a scan rate of $100 \mathrm{mV} / \mathrm{s}$. During the electrochemical polymerization process, the surface of the $\mathrm{Cu}-\mathrm{NPs} / \mathrm{GCE}$ gradually becomes green indicating the deposition of the PANI/NaNO NPs/PAN/GCE was thoroughly washed with distilled water to remove unbound matter. The recognition sites in the imprinted matrix were formed after removing the template from the imprinted film. Therefore, the selection of a suitable solution and method to completely elute the template from the imprinted film is very important. To remove the nitrate ions the modified sensor was immersed in a solution of hydrochloric acid $(0.5 \mathrm{M})$ for 24 hours, leaving an impression on the surface shape corresponding to the template shape. Then, the imprinted Cu-NPs/PAN/GCE was rinsed with distilled water and dried under nitrogen for the following experiments. As a control, the nonimprinted polymer modified electrode (NIP) was also prepared using the same procedure but without nitrate.

2.4. Real Samples Preparation. Water samples were used for environmental sample testing. The well water and mineral water were used without any pretreatment. The samples were first filtered and mixed with $0.1 \mathrm{M} \mathrm{Na}_{2} \mathrm{SO}_{4}$ electrolyte solution $(\mathrm{pH}=5)$. The water samples were spiked with $\mathrm{NO}_{3}{ }^{-}$. EIS method was employed to electrochemically detect nitrate, at optimum conditions. 


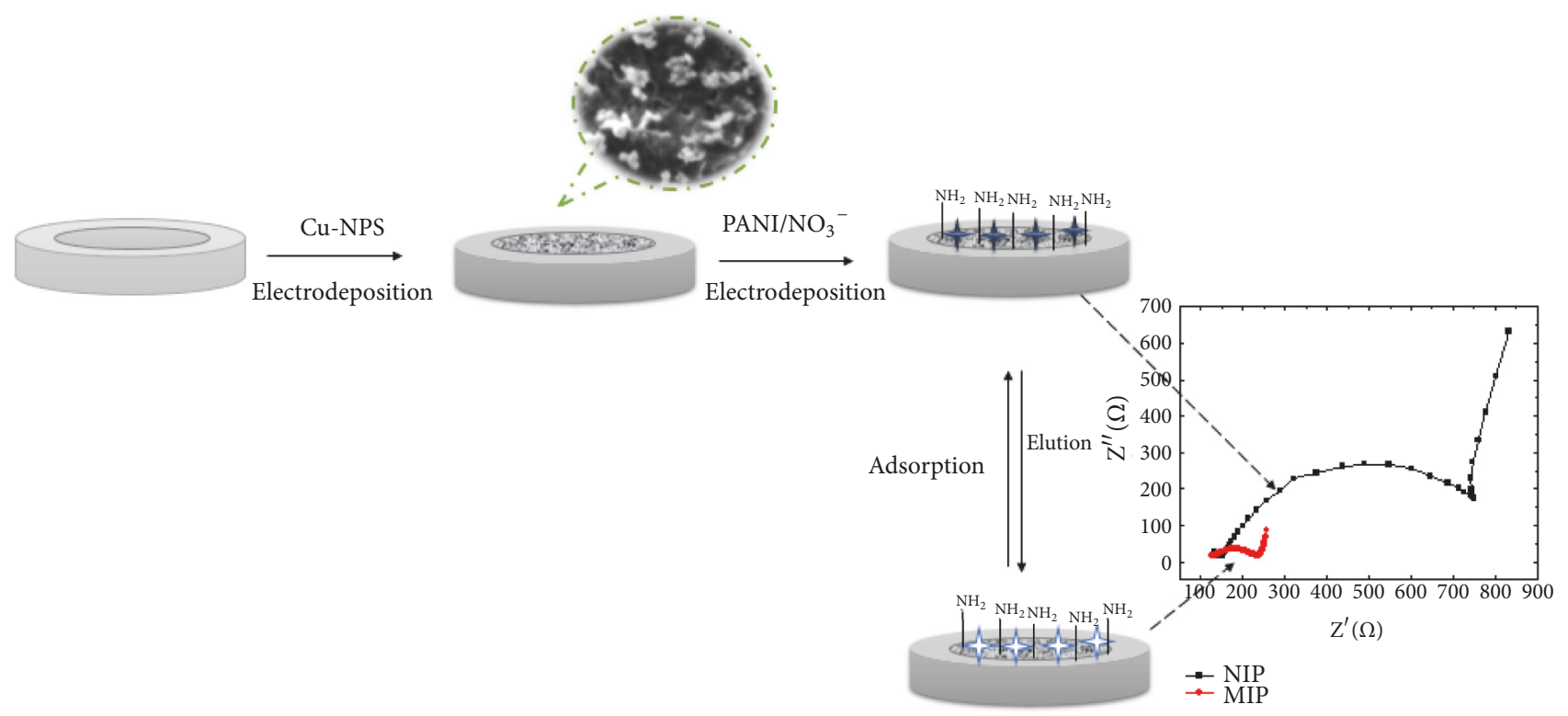

Scheme 1: Schematic illustration of the proposed IIP-GCE/Cu-NPs/PANI modified electrode for nitrate sensor.

\section{Results and Discussion}

3.1. Characterization of IIP. New ion-imprinted polymer for the electrochemical detection of nitrate was synthesized and characterized. In the first step Copper NPs were electrodeposited on the GCE surface via chronoamperometry technique by using $\mathrm{CuSO}_{4}$. As sensing substrate, the obtained nanoparticles further exhibited excellent benefit for the electropolymerization of PANI owing to the good absorption between the $\mathrm{Cu}-\mathrm{NPs}$ and the PANI polymer. In the second step the electrodeposition of PANI on the modified electrode through cyclic voltammetry technique with good stability mechanical flexibility and electrical conductivity was successfully achieved on $\mathrm{Cu}$-NPs coated electrode surface. The overall modification process was schematically presented in Scheme 1. In order to characterize the prepared copper nanoparticles and molecular imprinted films, different techniques involving SEM and UV-vis were conducted.

3.2. Morphological Characterization (SEM). To investigate the morphology of the modified GCE surface, SEM images were recorded. Figure 1 displays the SEM images of the GCE/Cu-NPs (a, b), the GCE/Cu-NPs/PANI (c, d), the NIPGCE/Cu-NPs/PANI (e), and the IIP- GCE/Cu-NPs/PANI (f), respectively. Clear changes in the surface morphology of the GCE before and after the surface modification were observed. Figures 1(a) and 1(b) show typical SEM images of electrodeposited copper nanoparticles with small white spots and a uniform size distributed homogeneously on the GCE surface. From Figures 1(c) and 1(d), it is clearly observed that the electropolymerized polyaniline film grown on the GCE/Cu-NPs surface exhibited a net structure change. Since PANI film was grown on the surface of $\mathrm{Cu}-\mathrm{NPs}$ modified electrode, the film became more uniform and porous. The typical features corresponding to $\mathrm{Cu}-\mathrm{NPs}$ are identified in Figure $1(\mathrm{~d})$. Figures 1(e) and 1(f) illustrate the SEM images of the imprinted films modified with GCE/Cu-NPs/PANI before and after removing the template, respectively. Their surface morphologies were different, which indicates the exclusion of the template from the matrix. After the removal of $\mathrm{NO}_{3}{ }^{-}$ions (Figure 1(f)), the imprinted surface was extremely rough, with polymer decorated with the copper nanoparticles. In contrast, before the removal of $\mathrm{NO}_{3}{ }^{-}$ions, $\mathrm{NO}_{3}{ }^{-}$imprinted pores appeared on the surface of the electrode as shown in Figure 1(e). The roughness of the IIP membrane enhances the sensitivity and the rebinding efficiency of the sensor.

3.3. Ultraviolet-Visible Studies. Figure 2 shows the UV-Vis spectrum of Cu-NPs, Cu-NPs/PANI, NIP-Cu-NPs/PANI, and IIP-Cu-NPs/PANI. The UV-Vis spectrum of $\mathrm{Cu}-\mathrm{NPs}$ displays an absorption band in the range of 386-475 nm which is a characteristic band of copper nanoparticles which confirms the formation of metal nanoparticles. After the addition of PANI, the intensity of the peak at $475 \mathrm{~nm}$ increased and two new peaks appeared at 272 and 790 $\mathrm{nm}$, respectively. The peak at $272 \mathrm{~nm}$ is attributed to the $\pi-\pi^{*}$ transition of the benzenoid ring. The peaks at 475 and $790 \mathrm{~nm}$ are assigned to the polaron transition of the PANI matrix [45-47]. A more significant change is observed in the composite spectrum as compared to $\mathrm{Cu}-\mathrm{NPs}$ alone. The UV-Visible spectra of NIP-Cu-NPs/PANI and IIP-CuNPs/PANI are shown in Figure 2. After the incorporation of $\mathrm{NO}_{3}{ }^{-}$ions into the composite matrix, the intensity of the peak with $\lambda_{\max }$ around $475 \mathrm{~nm}$ decreased as compared to that of $\mathrm{Cu}-\mathrm{NPs} / \mathrm{PANI}$, which reveals the intercalation of the $\mathrm{NO}_{3}{ }^{-}$ions. In addition, a bathochromic shift from 272 to 325 $\mathrm{nm}$ indicates the strong interaction between the composite matrix and $\mathrm{NO}_{3}{ }^{-}$. After the removal of $\mathrm{NO}_{3}{ }^{-}$ions from the composite matrix, the spectrum being identical to that obtained for the Cu-NPs/PANI matrix without template. This result corroborates the formation of artificial complementary sites to recognize $\mathrm{NO}_{3}{ }^{-}$ions in solution. 


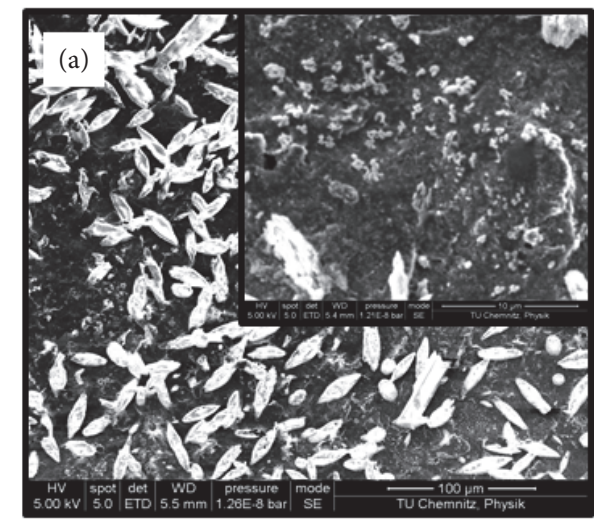

(a)

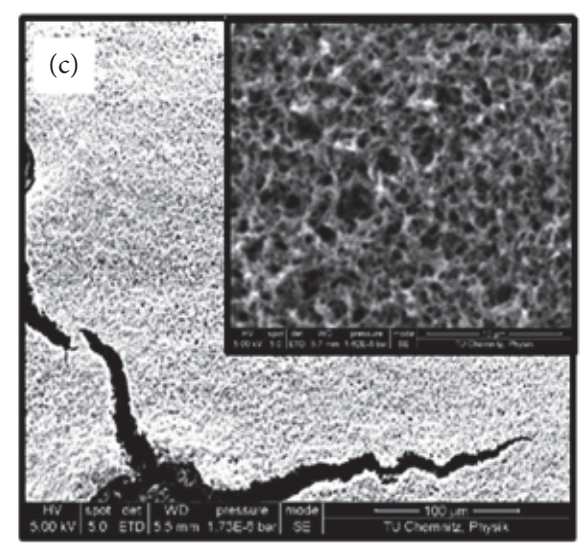

(c)

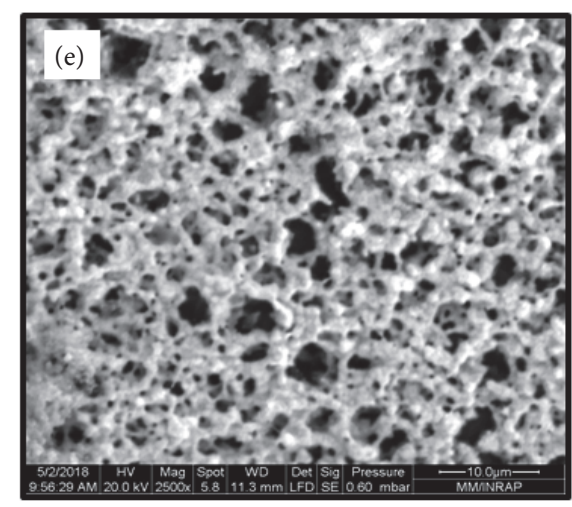

(e)

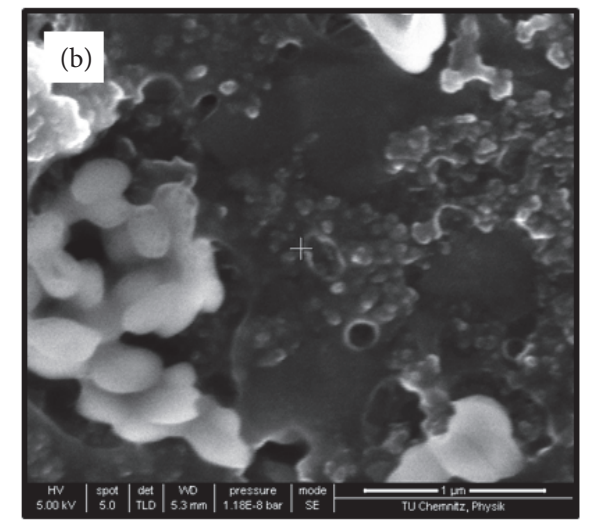

(b)

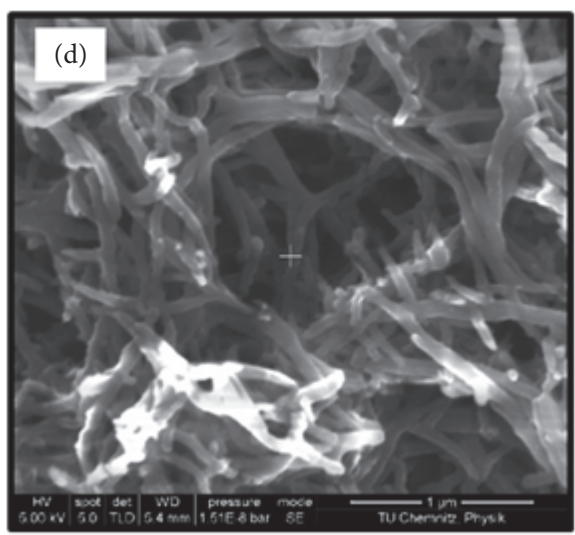

(d)

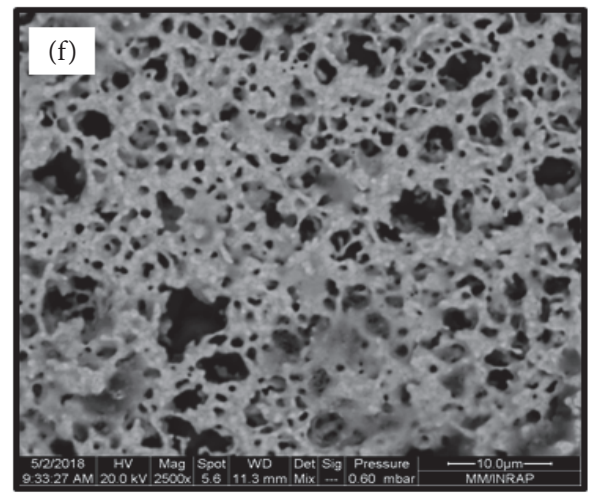

(f)

FIGURE 1: SEM images of the modified rotating GC electrode surface with different materials: GCE/Cu-NPs (a, b), GCE/Cu-NPs/PANI (c, d), NIP-GCE/Cu-NPs/PANI (e), and IIP-GCE/Cu-NPs/PANI (f) layers.

3.4. Electropolymerization of Ion-Imprinted Polyaniline. A molecularly imprinted polyaniline modified GGE/Cu-NPs was made in a solution of $0.5 \mathrm{M} \mathrm{H}_{2} \mathrm{SO}_{4}$ using potential cycling between -0.2 and $1 \mathrm{~V}$ vs. $\mathrm{Ag} / \mathrm{AgCl} / 3 \mathrm{M} \mathrm{KCl}$ with a scan rate of $100 \mathrm{mV} / \mathrm{s}$. Figure 3 demonstrates ten cycles obtained during the synthesis of the IIP and the NIP matrices. The peak current increases progressively suggesting the growth of the conducting polymer matrix. The voltammogram shows some basic information like the features of the PANI oxidation and reduction which has three oxidation states: the reduced leucoemeraldine (LEB), the oxidized emeraldine (EM), and the oxidized pernigraniline (PNG). The first set of redox peaks corresponds to the conversion of LEB to EM and begins at a potential of $0.2 \mathrm{~V}$. The second set of redox peaks corresponds to the conversion of EM to PNG and begins at a potential of $0.52 \mathrm{~V}$ and $0.84 \mathrm{~V}$ as can be seen in Figure 3. Continuous cycling of the peaks with increasing redox current signifies that the polyaniline film formed at the 


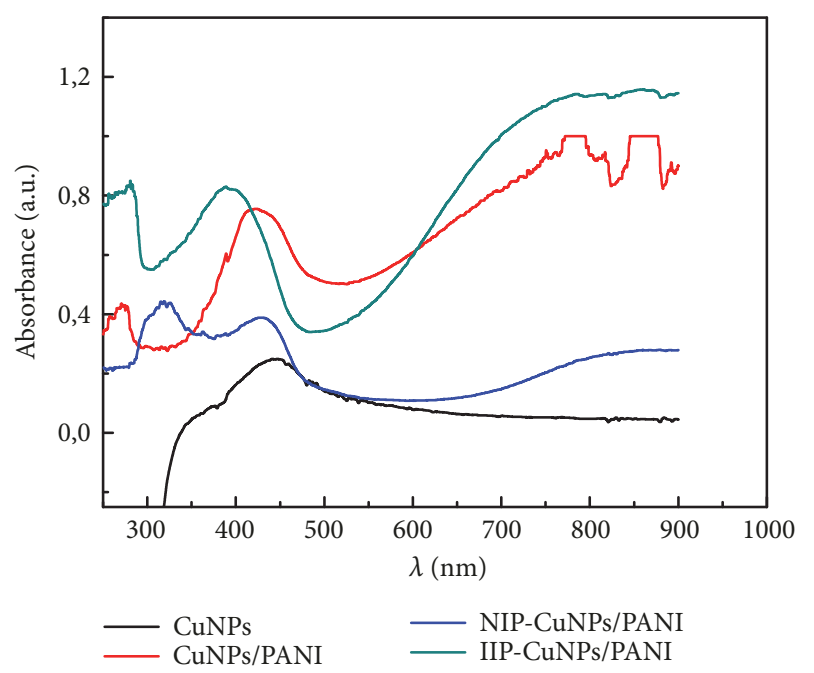

FIGURE 2: UV-Visible spectra of the electrochemically deposited film of PANI/Cu-NPs, NIP-PANI/Cu-NPs, and IIP-PANI/Cu-NPs.

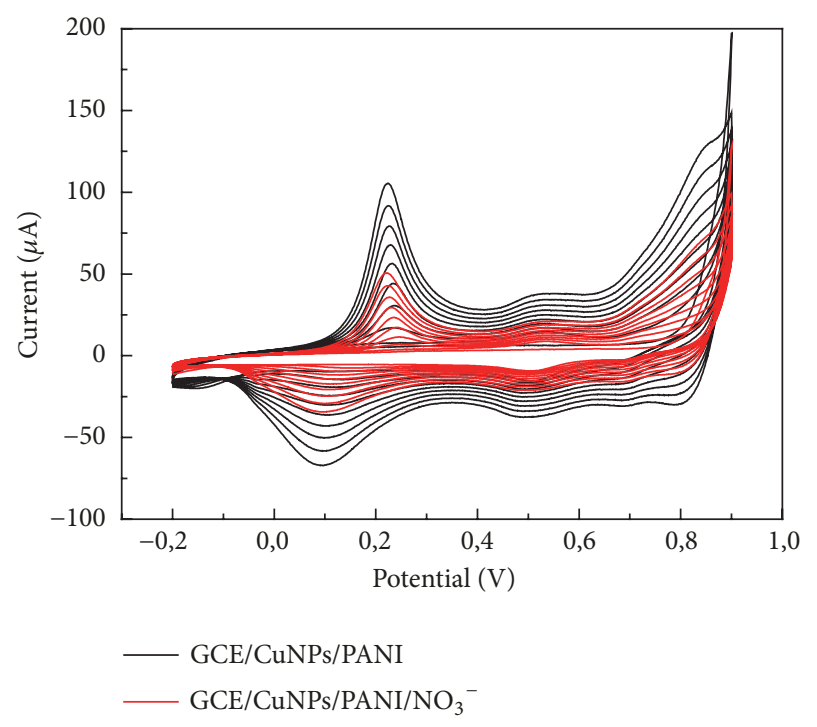

FIGURE 3: Cyclic voltammograms taken during the electropolymerization of aniline (0.1M) in the absence (black) and presence (red) of $(1 \mathrm{mM}) \mathrm{NaNO}_{3}$ onto GCE/Cu-NPs. Scan rate: $100 \mathrm{mV} / \mathrm{s}$. Supporting electrolyte: $0.5 \mathrm{M} \mathrm{H}_{2} \mathrm{SO}_{4}$. Number of scans: 10 .

surface of the electrode was thicker, uniform, conductive, and electroactive. For imprinted electropolymerization, the effect of nitrate ion can be easily distinguished. It was observed that oxidation and reduction peaks were lower when nitrate ions were present in the polymerization solution. The nitrate ions are trapped in the polymer matrix through noncovalent interactions between $-\mathrm{NH}_{2}$ groups of the polymer and the oxygen atoms of the nitrate.

3.5. Optimization of the Experimental Conditions of Nitrate Measurement. Different influencing factors including the electropolymerization scan cycles, the scan rate, the template concentration, and the monomer concentration were investigated to fabricate an efficient sensor.
3.5.1. Optimal Conditions for Monomer and Template Concentration. The electrochemical performances of the IIP modified sensor can be affected by the monomer concentration during the electrodeposition process. In fact, the aptitude of the binding template molecules is substantially relying on the number of cavities created during the electropolymerization. Therefore, to determine the effect of monomer concentration on the response of the IIP sensor to $\mathrm{NO}_{3}{ }^{-}$, the films were grown in solutions containing constant concentration of $\mathrm{NO}_{3}{ }^{-}$ions, varying the aniline concentrations in the range from $1 \mathrm{mM}$ to $0,2 \mathrm{M}$. Figure $4(\mathrm{a})$ is a plot of the $\mathrm{R}_{\mathrm{ct}}$ (electron transfer resistance) values and the current response as a function of aniline concentration. When the aniline concentration increased, the $\mathrm{R}_{\mathrm{ct}}$ values decreased and the current increased, whereas $R_{c t}$ increased with the decrease in the current when the concentration of aniline was up to $0.1 \mathrm{M}$. It can be concluded that the optimum monomer concentration for the determination of nitrate was about $0,1 \mathrm{M}$. Inadequate amount of functional monomer (aniline) led to insufficient number of available binding sites to combine template molecules. On the contrary, excessive monomers resulted in a thick IIP film, and consequently many binding sites were buried in the polymeric matrix and became noneffective.

To find the optimal composition for IIP-GCE/CuNPs/PANI which can produce the maximum sensitivity toward the detection of $\mathrm{NO}_{3}{ }^{-}$added to aniline in the electropolymerization system, different concentrations of nitrate ions ranging between $0.1 \mathrm{mM}$ and $10^{-2} \mathrm{M}$ were studied (Figure 4(b)). When the concentration of $\mathrm{NO}_{3}{ }^{-}$increased, the $R_{c t}$ decreased and reached a minimum of $0.1 \mathrm{mM}$ and the current response increased and reached a maximum of $0.1 \mathrm{mM}$. However, a rapid increase of $\mathrm{R}_{\mathrm{ct}}$ and a decrease in the current response can be observed when the nitrate concentration exceeded $0.1 \mathrm{M}$, so this concentration was selected as the optimal value during the preparation of the IIP-GCE/Cu-NPs/PANI sensor.

3.5.2. Effect of Scan Rate and Electropolymerization Cycles. Scan rate studies were carried out to determine whether the process on GCE/Cu-NPs/PANI was under diffusion control. The effect of scan rate on the peak current of $\mathrm{NO}_{3}{ }^{-}$was investigated by cyclic voltammetry technique in $\mathrm{Na}_{2} \mathrm{SO}_{4}(\mathrm{pH}$ 5.0) containing $10^{-3} \mathrm{M}$ of nitrate with different scan rates ranging from 1 to $1000 \mathrm{mV} / \mathrm{s}$ (Figure 5(a)). The oxidation peak currents increased with increasing the scan rate at the IIP in the nitrate solution, while their oxidation peak potentials gradually shift to positive values. This behavior indicates that the modified electrode reaction of $\mathrm{NO}_{3}{ }^{-}$is a surface confined process. Besides, a plot of $\mathrm{I}_{\mathrm{pa}}$ versus the square root of the scan rate $\left(v^{1 / 2}\right)$ in the range of 10 to $1000 \mathrm{mV} / \mathrm{s}$ gave a straight line with a slope of 0.258 , and a good correlation coefficient $\left(\mathrm{R}^{2}=0.99963\right)$ was observed (insert Figure 5(a)).

The thickness of the imprinted film is an important factor which can affect the sensitivity and the stability of the imprinted sensors. Figure 5(b) shows the effect of the number of scan cycles on the cyclic voltammograms recorded during the electropolymerization of aniline on the $\mathrm{Cu}-\mathrm{NPs} / \mathrm{GCE}$ in the presence of the nitrate ions. The oxidation peaks 


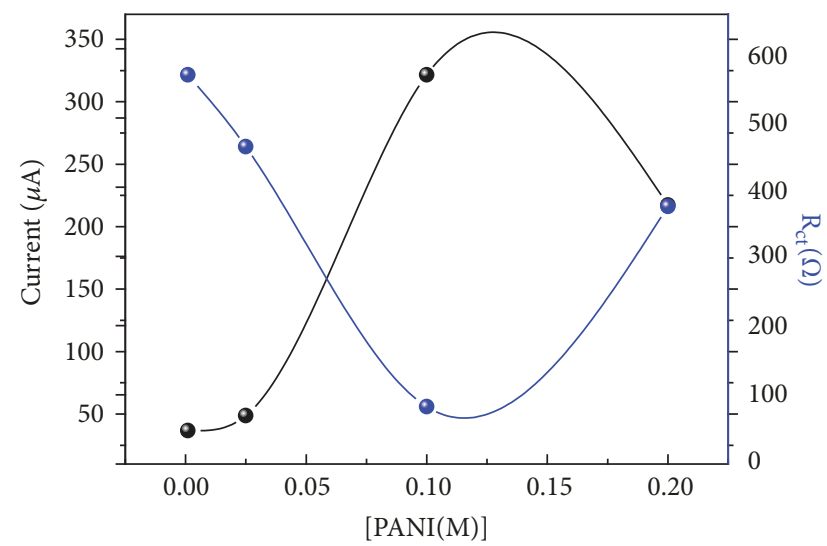

(a)

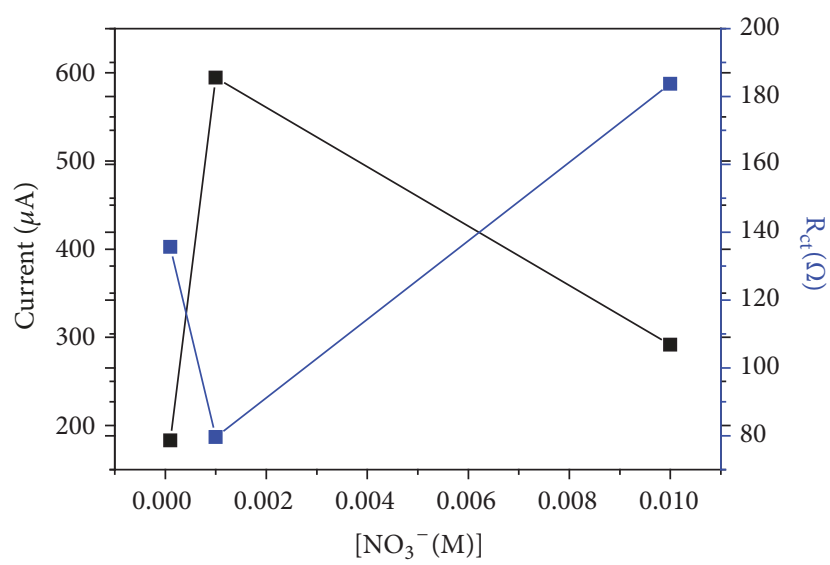

(b)

Figure 4: (a) Effect of PANI, (b) $\mathrm{NO}_{3}{ }^{-}$concentration on the $\mathrm{R}_{\mathrm{ct}}$ values and peak currents of electrocatalytic reduction of nitrate in $0.1 \mathrm{M}$ $\mathrm{Na}_{2} \mathrm{SO}_{4}$ solution $(\mathrm{pH}=5)$.

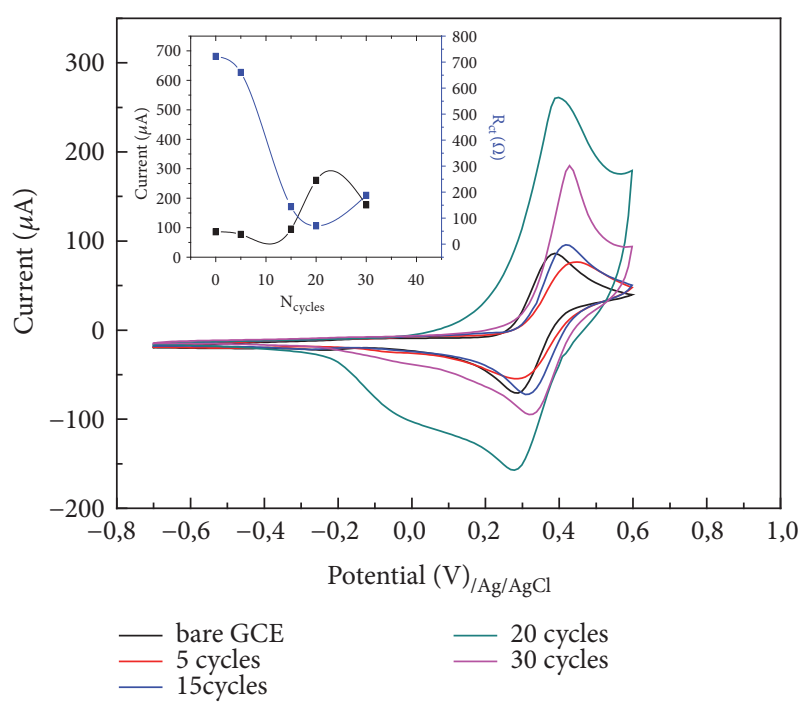

(a)

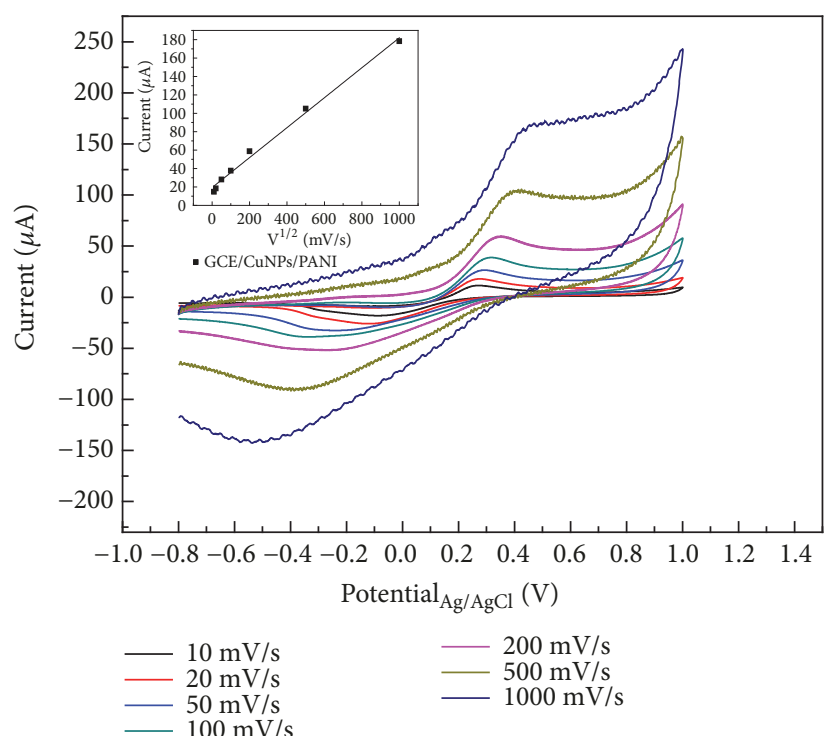

(b)

FIGURE 5: (a) Effect of the electropolymerization cycles in $5 \mathrm{mM}\left[\mathrm{Fe}(\mathrm{CN})_{6}\right]^{3-/ 4-}$ containing $0.1 \mathrm{M} \mathrm{KCl}$ solution. (b) CV responses obtained from GCE/Cu-NPs/PANI in the presence of $1 \mathrm{mM}$ nitrate as a function of scan rate ranging from 10 to $1000 \mathrm{mV} / \mathrm{s}$ in $0.1 \mathrm{M} \mathrm{Na}_{2} \mathrm{SO}_{4}$ solution $(\mathrm{pH}=5)$.

increase with cyclic scanning number from 3 to 10, which indicates the successful formation of IIP films with a suitable thickness. When the scan number is less than ten, the imprinted polymer membrane becomes very thin and easy to break when extracting the template. If the cycles number is more than ten, the imprinted polymer membrane becomes too thick, and the template molecules cannot be completely removed from the film. Therefore, the number of cycles for the prepared IIP-GCE/Cu-NPs/PANI sensor was adjusted to 10 cycles in the following investigations.

3.6. Effect of $p H$ on the IIP Electrochemical Performances. The electrochemical performances of the sensitive imprinted layer can be influenced by the working $\mathrm{pH}$. Thus, to select a suitable $\mathrm{pH}$ for nitrate sensing, the effect of $\mathrm{pH}$ values was studied by a series of LSVs on the imprinted electrode in $10^{-2}$ $\mathrm{M}$ of nitrate solution at different working $\mathrm{pH}$ values from 2 to 8 , using $0.1 \mathrm{M} \mathrm{Na}_{2} \mathrm{SO}_{4}$ as supporting electrolyte. As visualized in Figure 6, by increasing the $\mathrm{pH}$ from 2 to 5 , the reduction peak current increased gradually and then decreased rapidly to reach a high peak at 5 . These observations suggest that, at a strong acidic media, hydrogen evolution come at less negative potential and it can trouble the reduction peak of nitrate. To guarantee the optimal imprinted sensor performances toward nitrate detection the $\mathrm{pH}$ value of 5.0 was chosen as the appropriate $\mathrm{pH}$. 


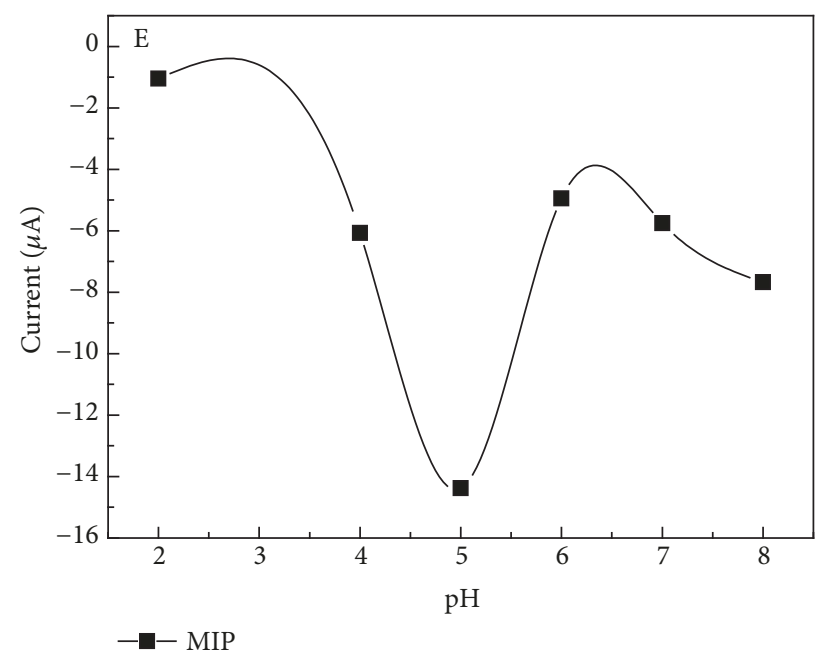

Figure 6: LSV current as a function of $\mathrm{pH}$ of IIP-GCE/Cu$\mathrm{NPs} / \mathrm{PANI}$ in $10 \mathrm{mM}$ nitrate solutions.

\subsection{Electrochemical Characterization of Various Modified} Electrodes. The electrochemical behavior of the modified electrodes was studied by cyclic voltammetry and impedance spectroscopy. CV is a convenient and effective technique used to investigate the modification processes of the electrodes. Figure 7(a) shows cyclic voltammograms of bare and modified GCE in $5 . \mathrm{mM}$ of $\left[\mathrm{Fe}(\mathrm{CN})_{6}\right]^{3-/ 4-}$ as a redox probe and $0.1 \mathrm{M} \mathrm{KCl}$ solution in a potential range -0.8 to 1V. The bare electrode shows a couple of quasi-reversible redox peaks at $+0.26 \mathrm{~V}$. As shown in curve $\mathrm{B}$, after the electrode was modified with $\mathrm{Cu}-\mathrm{NPs}$, another redox peak appeared at $+0.75 \mathrm{~V}$ and the peak current intensity at $0.26 \mathrm{~V}$ increased, which indicated the presence of copper nanoparticles on the surface of GCE. After electropolymerization of aniline in the surface of $\mathrm{Cu}-\mathrm{NPs} / \mathrm{GCE}$ (curve $\mathrm{C}$ ), the $\mathrm{Cu}$ NPs/PANI/GCE exhibited a much higher current response due to the excellent electrical conductivity of PANI and $\mathrm{Cu}$ NPs. The decrease in the current response from curve $\mathrm{C}$ to curve $\mathrm{D}$ is related to the occupation of the imprinted cavities by $\mathrm{NO}_{3}{ }^{-}$after the rebinding process. However, the redox peaks of $\left[\mathrm{Fe}(\mathrm{CN})_{6}\right]^{3-/ 4-}$ decreased obviously after the electropolymerization of aniline in the presence of nitrate. This result indicates that the modified IIP film before the removal of the template is less conductive and can block the access of reactants to the electrode surface (curve D). On the other hand, the current response of the electrode increased apparently when the nitrate was removed (curve E). This behavior is due to the increase of vacant recognition sites number after removing the template, which enhances the diffusion of $\left[\mathrm{Fe}(\mathrm{CN})_{6}\right]^{3-/ 4-}$ and promotes the redox reaction of the $\left[\mathrm{Fe}(\mathrm{CN})_{6}\right]^{3-/ 4-}$ on the sensor surface.

The relation between the peak current and electrode surface area obeys the Randles-Sevcik equation [45]:

$$
I_{p}=\left(2.69 \times 10^{5}\right) n^{3 / 2} A D^{1 / 2} v^{1 / 2} C
$$

where $I_{p}$ is the peak current, $n$ is the electron transfer number, $A$ is the effective surface area $\left(\mathrm{cm}^{2}\right), D$ is the diffusion coefficient of $\mathrm{K}_{3}\left[\mathrm{Fe}(\mathrm{CN})_{6}\right]$ in the solution $\left(0.650 .10^{-5} \mathrm{~cm}^{2}\right.$ $\left.\mathrm{s}^{-1}\right), \mathrm{C}$ is the concentration of $\mathrm{K}_{3}\left[\mathrm{Fe}(\mathrm{CN})_{6}\right]\left(\mathrm{mol} / \mathrm{cm}^{3}\right)$, and $v$ is the scan rate $\left(\mathrm{mV} \mathrm{s}^{-1}\right)[48,49]$. Based on (1), the effective surface areas of GCE, GCE/Cu-NPs, GCE/Cu-NPs/PANI, NIP-GCE/Cu-NPs/PANI, and IIP-GCE/Cu-NPs/PANI were calculated to be $0.035,0.027,0.04,0.03$, and $0.14 \mathrm{~cm}^{2}$, respectively. The results are shown in Figure 7(b) for which the peak currents of the bare GCE are lower than those theoretically calculated from the Randles-Sevcik (1). The peak current of $\mathrm{Cu}-\mathrm{NPs} / \mathrm{PANI}$ modified GCE presents higher redox signal than that of other electrodes. This result indicates that the redox reactions are not wholly under diffusion control. This is most possibly due to the adsorption of $\left[\mathrm{Fe}(\mathrm{CN})_{6}\right]^{3-/ 4-}$ leading to preconcentration within the modified composite layers because of the highly porous structure.

Consistent with CV study, electrochemical impedance spectroscopy (EIS) is an effective method to analyze the charge transfer resistance of the interface electrode/solution, which can be simulated using the Randles' equivalent circuit. Herein, EIS data were typically used to follow the $R_{c t}$ changes occurring at the interface after each stage of electrochemical modification. From the shape of an impedance spectrum, the electron transfer kinetics and the diffusion characteristics can be determined. In EIS studies, the semicircle portion at high frequency region represents the electron transfer resistance $\left(\mathrm{R}_{\mathrm{ct}}\right)$ of the electrode, and the linear tail at lower frequencies indicates the diffusion limited process [50-52]. Figure 7(c) depicts the Nyquist diagrams recorded at the frequency range from 0.1 to $10^{5} \mathrm{~Hz}$ with $100 \mathrm{mV}$ amplitude using bare and differently modified GC electrodes applying an excitation potential of $0.238 \mathrm{~V}$ (vs. $\mathrm{Ag} / \mathrm{AgCl}$ reference electrode. All EIS measurements were carried out using $5.10^{-3} \mathrm{M}\left[\mathrm{Fe}(\mathrm{CN})_{6}\right]^{3-/ 4-}$ as redox probe in $0.1 \mathrm{M} \mathrm{KCl}$ solution. In the Nyquist plot, the diameter of the semicircle defines the electron transfer resistance $\left(\mathrm{R}_{\mathrm{ct}}\right)$ [53-55]. It is clearly observed that the GC electrode exhibits a small semicircle (curve A) indicating a fast charge transfer process. Compared with that observed for bare GCE, Cu-NPs modified GCE leads to an enhancement in the charge transfer resistance (curve B). After the electrodeposition of PANI layer, the semicircle diameter belonging to GCE/Cu-NPs/PANI decreases dramatically. And the corresponding $\mathrm{R}_{\mathrm{ct}}$ value is of the order of $71.7 \Omega$ (curve C). This value is attributed to the high conductivity of PANI that coated the surface of the modified electrode. Thus, it demonstrates obvious implementation of very fast charge transfer effect between the redox probe and the GCE/Cu-NPs/PANI modified electrode. With the modified electrode by the imprinted film (curve D), the diameter of the semicircle increased, which proves the nonconductivity of the film covering the electrode surface. However, after the removal of the template $\mathrm{NO}_{3}{ }^{-}$(curve E), the diameter of the semicircle of IIP-GCE/Cu-NPs/PANI decreased $\left(R_{c t}=108.7 \Omega\right)$, indicating the formation of a large number of the imprinted cavities on the film covering the electrode surface. And that enhances the diffusion rate of $\left[\mathrm{Fe}(\mathrm{CN})_{6}\right]^{3-/ 4-}$ through the membranes and makes electron transfer easy. 


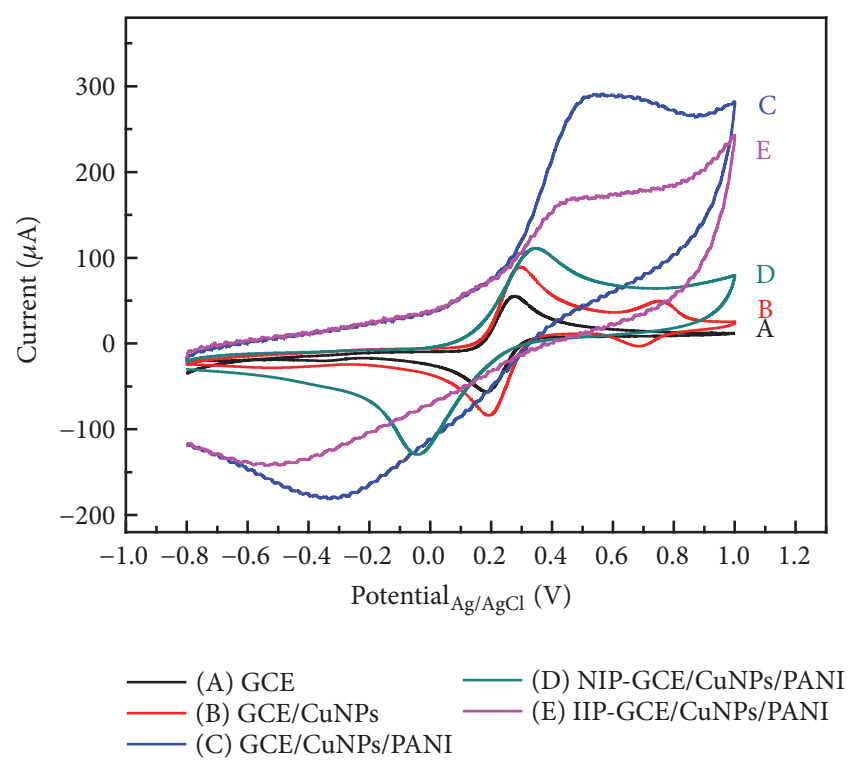

(a)

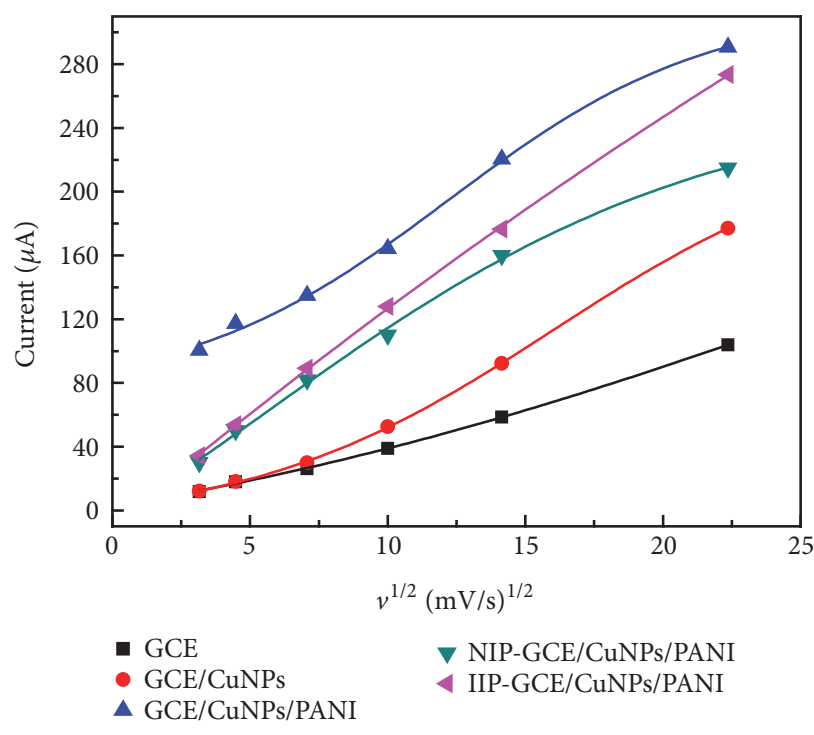

(b)

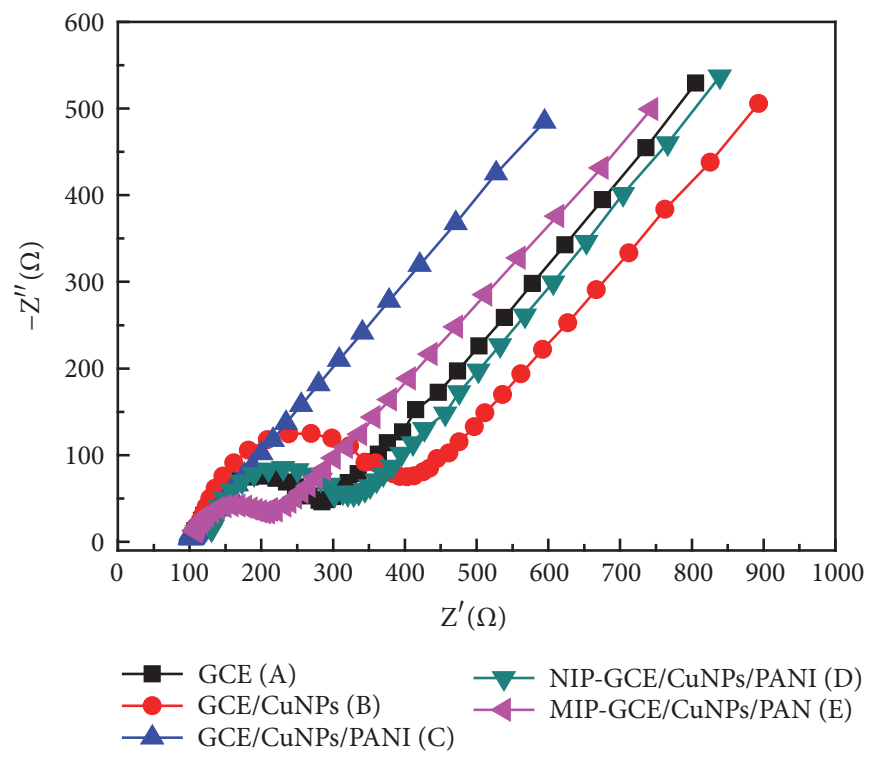

(c)

FIguRE 7: Cyclic voltammograms (a), (b) Randles-Sevcik plots of CV peak current vs. square root of the scan rate and Nyquist plots (c) recorded in $5.10^{-3} \mathrm{M}\left[\mathrm{Fe}(\mathrm{CN})_{6}\right]^{-3 /-4}$ and $0.1 \mathrm{M} \mathrm{KCl}$ for GCE (A), GCE/Cu-NPs (B), GCE/Cu-NPs/PANI (C), NIP-GCE/CNPs/PANI (D), and IIP-GCE/Cu-NPs/PANI (E).

3.8. Permeability of Various Modified Electrodes. The rotating disk electrode (RDE) experiments have been extensively used to investigate the intrinsic kinetics of the electrocatalytic process based on the suppression of the mass transfer control [56]. Therefore, the mass transfer process through the bare and modified electrodes to the surface of the electrode was investigated by linear sweep voltammetry. The experiments were conducted using an RDE controller and rotator. The $\left[\mathrm{Fe}(\mathrm{CN})_{6}\right]^{3-/ 4-}$ couple was chosen for this study because it reacts in a simple, reversible electrochemical process and the diffusion properties in solution have been well documented. Figure 8(a) illustrates the voltammograms obtained for bare and modified rotating GCE, performed in aqueous $5 \mathrm{mM}$ $\left[\mathrm{Fe}(\mathrm{CN})_{6}\right]^{3-/ 4-}$ and $0.1 \mathrm{M} \mathrm{KCl}$ solution, recorded at $20 \mathrm{mV} / \mathrm{s}$ in the potential range from -0.8 to $1.0 \mathrm{~V}$. The response of the $\left[\mathrm{Fe}(\mathrm{CN})_{6}\right]^{3-/ 4-}$ redox probe gradually decreased after the modification steps. The permeability $\left(\mathrm{P}_{\mathrm{m}}\right)$ of the modified electrodes was determined using the typical equations introduced by Gough and Leypoldt (2) [47]:

$$
\frac{1}{i_{L}}=\frac{1}{n F A C P_{m}}+\frac{1}{0.62 A C F n v^{-1 / 2} D^{2 / 3} \omega^{-1 / 2}}
$$

where $i_{L}$ is the membrane diffusion limited current, $A$ is the electrode area, $D\left(1.8 .10^{-5} \mathrm{~cm}^{2} \mathrm{~s}^{-1}\right)$ corresponds to the 


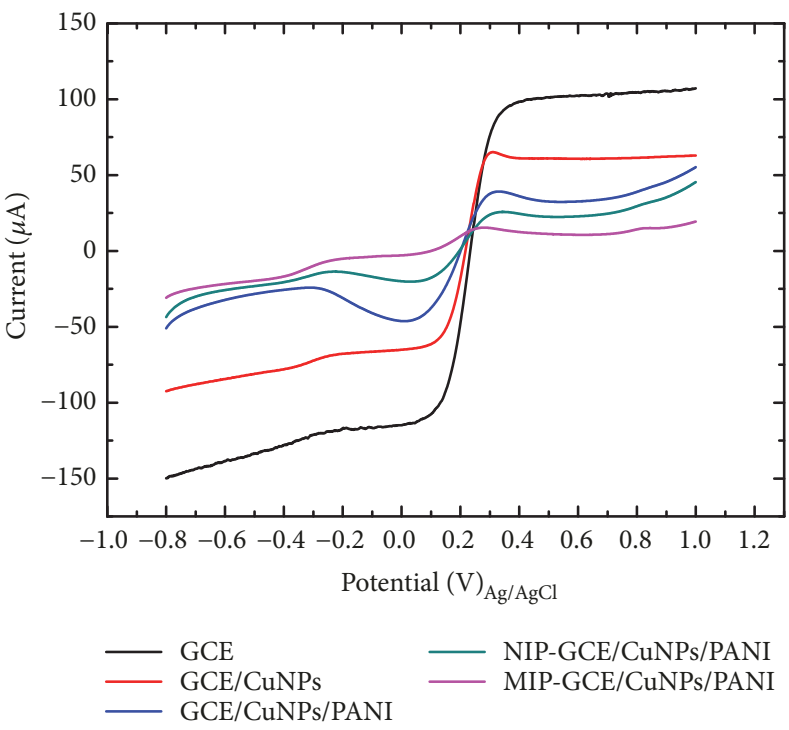

(a)

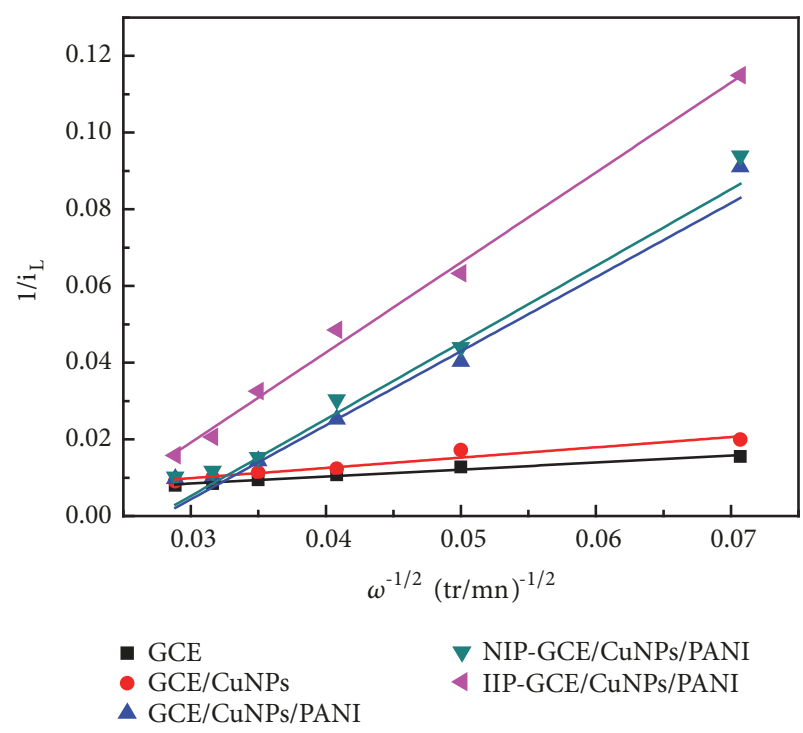

(b)

FIGURE 8: (a) LSVs curves recorded at bare and modified GC electrodes (scan rate:10 $\mathrm{mV} / \mathrm{s}$ ) in $5 \mathrm{mM}\left[\mathrm{Fe}(\mathrm{CN})_{6}\right]^{3-/ 4-}+0,1 \mathrm{M} \mathrm{KCl} \mathrm{solution} \mathrm{at}$ different rotation rates, (b) Koutecky-Levich plots of LSV peak current vs. logarithm of $\mathrm{NO}_{3}{ }^{-}$concentration of the modified electrodes.

TABLE 1: Coefficients of permeability and limit current of bare and modified electrodes in $5 \mathrm{mM}\left[\mathrm{Fe}(\mathrm{CN})_{6}\right]^{3-/ 4-}$ containing $0.1 \mathrm{M} \mathrm{KCl}$ solution.

\begin{tabular}{lcc}
\hline Membrane & $\mathrm{I}_{\mathrm{L}}(\mathrm{mA})$ & $\mathrm{P}_{\mathrm{m}}\left(\mathrm{cms}^{-1}\right)$ \\
\hline GCE/CuNPs & 0.126 & 0.113 \\
GCE/CuNPs/PANI & 0.083 & $0.79 .10^{-4}$ \\
NIP-GCE/CuNPs/PANI & 0.045 & $10^{-3}$ \\
IIP-GCE/CuNPs/PANI & 0.018 & $0.27 .10^{-3}$ \\
\hline
\end{tabular}

diffusion coefficients of the substrate in the bulk solution, $C$ is the concentration of the probe, $v\left(0.01 \mathrm{~cm}^{2} \mathrm{~s}^{-1}\right)$ is the kinetic viscosity of the solution, $F$ is the Faraday constant, $n$ is the number of electrons, and $\boldsymbol{\omega}$ is the rotation rate of the RDE [42]. The intercept of a Koutecky-Levich plot of $\left(1 / \mathrm{i}_{\mathrm{L}}\right)$ versus $\left(1 / \omega^{-1 / 2}\right)$ leads to $\left(1 / i_{L}\right)$ at the infinite rotation rate, the effect of diffusion of the probe in solution becomes negligible, and $i_{L}$ depends on the diffusion of the probe through the film [57]. The membrane diffusion limited current can be expressed by the relation given below.

$$
i_{L}=n F A C P_{m}
$$

To estimate the $\mathrm{P}_{\mathrm{m}}$ value of the different matrices under optimal condition, Koutecky-Levich plots of the inverse of the current $\left(1 / i_{L}\right)$ versus the inverse of the square root of the rotation rate $\left(1 / \omega^{-1 / 2}\right)$ were explored for bare and modified rotating GC electrode, using the data extracted from the experimental curves plotted in Figure 8(b). Linear fittings were obtained for bare and modified electrodes and the straight lines were parallel to each other, which confirms that the redox reaction is irreversible. Table 1 summarizes the $\mathrm{P}_{\mathrm{m}}$ values obtained for the bare and the different modified electrodes.
3.9. Comparison of the Electrochemical Behaviors of IIP and NIP for Nitrate Detection. The glassy carbon electrodes disk modified with IIP and NIP were incubated in different concentrations of $\mathrm{NO}_{3}{ }^{-}$solutions from $1 \mu \mathrm{M}$ to $0.1 \mathrm{M}$, while stirring the solution continuously. To investigate the detection ability of IIP and NIP, LSV and EIS techniques were applied to detect nitrate ions under optimum conditions. In EIS measurements, all the Nyquist plots are fitted by using the classical Randles' equivalent circuit [R(Q[RW])] depicted in Figure 9(a). The obtained results of the mentioned electrodes are shown in Figure 9(b) and Figure 9(c). Figure 9(b) shows a series of impedance spectra recorded for different $\mathrm{NO}_{3}{ }^{-}$concentrations ranging from $1 \mu \mathrm{M}$ to $0.1 \mathrm{M}$ in $\mathrm{Na}_{2} \mathrm{SO}_{4}$ solution $(0.1 \mathrm{M})$ at $\mathrm{pH}=5$. It is reported that the electrochemical reduction of nitrate to nitrite ions on the surface of the IIP-GCE/Cu-NPs/PANI exhibited a twoelectron transfer process, as shown in the following equation.

$$
\mathrm{NO}_{3}{ }^{-}+2 \mathrm{H}^{+}+2 \mathrm{e} \longrightarrow \mathrm{NO}_{2}{ }^{-}+\mathrm{H}_{2} \mathrm{O}
$$

The $\mathrm{R}_{\mathrm{ct}}$ (diameter of the semicircle) in the absence of $\mathrm{NO}_{3}{ }^{-}$ is relatively small $(35 \Omega)$. This value can be attributed to the free electron transfer at the interface electrode/solution. The increase of $\mathrm{NO}_{3}{ }^{-}$concentration induces the increase 


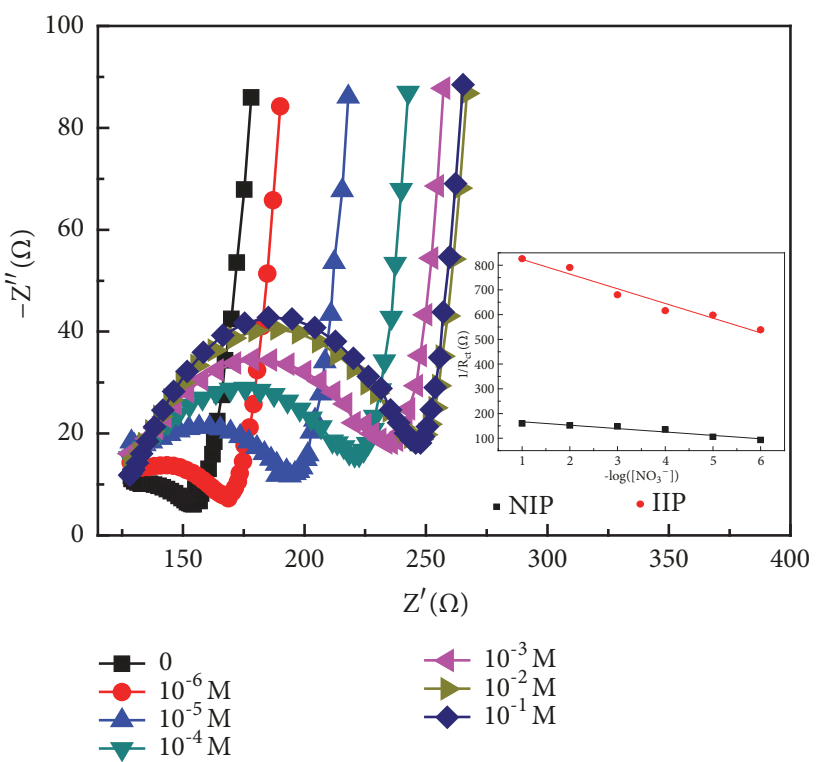

(a)

(b)

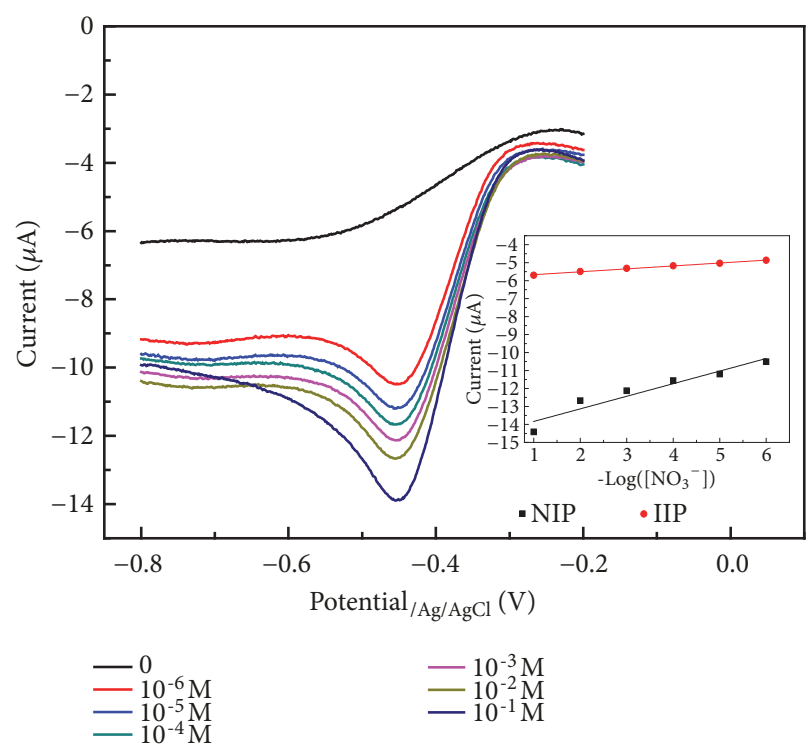

(c)

Figure 9: (a) Classical Randles' equivalent circuit, EIS (b) and LSV (c) responses of IIP and NIP as a function of various concentrations of $\mathrm{NO}_{3}{ }^{-}$in $\mathrm{Na}_{2} \mathrm{SO}_{4}$ solution $(\mathrm{pH}=5)$.

of the $\mathrm{R}_{\mathrm{ct}}$ value, which corresponds to the rebinding of $\mathrm{NO}_{3}{ }^{-}$ions to the imprinted sites. When the concentration of $\mathrm{NO}_{3}{ }^{-}$increases, more cavities would be filled up, giving rise to a more significant increase in the $R_{c t}$ values. The insert of Figure 9(b) is a graphical representation of the variation in $1 / R_{c t}$ value (obtained through Nova analysis) with $\mathrm{NO}_{3}{ }^{-}$concentration by IIP and NIP electrodes. The linear response range for $\mathrm{NO}_{3}{ }^{-}$detection was obtained in the range from $1 \mu \mathrm{M}$ to $100 \mathrm{mM}$ with a sensitivity of 0.15 and $0.88 \mathrm{~mA} \mathrm{M}^{-1}$ for the NIP and the IIP, respectively. A linear regression equation was obtained with a detection limit as low as $2 \cdot 10^{-7}$ and $3,1.10^{-7} \mathrm{~mol} \mathrm{~L}^{-1}$ for the NIP and the IIP, respectively. In addition, the LSV method was carried out on the IIP sensor to evaluate its sensitivity for the nitrate ions. The electrochemical feedback can be established by exploring the dependence of the peak current values with the nitrate concentration. As shown in Figure 9(c), the reduction peak at $-0.47 \mathrm{~V}$ decreased linearly with increasing $\mathrm{NO}_{3}{ }^{-}$ concentration in the range from $1 \mu \mathrm{M}$ to $0.1 \mathrm{M}$. The insert of Figure 9(c) exhibits the corresponding calibration plot corresponding to the IIP and the NIP structures manipulate at $\mathrm{pH}$ equal to 5. A linear relationship was observed between peak current and the logarithm of the concentration of $\mathrm{NO}_{3}{ }^{-}$ in the concentration range from $1 \mu \mathrm{M}$ to $100 \mathrm{mM}$, with a 
TABLE 2: Comparison of some characteristics of the different electrodes for the detection of $\mathrm{NO}_{3}{ }^{-}$.

\begin{tabular}{lcccc}
\hline Electrode & Method & $\begin{array}{c}\text { Detection } \\
\text { limit }(\mu \mathrm{M})\end{array}$ & $\begin{array}{c}\text { Linearity } \\
(\mu \mathrm{M})\end{array}$ & References \\
\hline Copper modified pencil graphite & Amperometry & $0.59 \mathrm{M}$ & $1-35$ & {$[42]$} \\
$\mathrm{PM}_{2.5} /$ Copper/CFMDE & SWV & 1.10 & $3-200$ & {$[43]$} \\
BIB/Copper & DPV & 6 & $13-3000$ & {$[1]$} \\
Copper-plated copper wire & LSV & 4.2 & $10-200$ & {$[44]$} \\
Copper nanowire & DPV & 1.35 & $8-5860$ & {$[8]$} \\
IIP-Copper & EIS & 31 & $1-100000$ & This work \\
nanoparticles/Polyaniline/GCE & LSV & 5 & $1-100000$ & \\
\hline
\end{tabular}

$\mathrm{PM}_{2.5}$ : Airborne particulate matter.

CFMDE: carbon fiber micro disk electrode.

TABLE 3: Recovery data for detection of $\mathrm{NO}_{3}{ }^{-}$in water samples using IIP-Cu-NPs/PANI/GCE in $\mathrm{Na}_{2} \mathrm{SO}_{4}$ solution $\mathrm{pH}=5$ as supporting electrolyte.

\begin{tabular}{lccc}
\hline Sample & Added $\left(\mathrm{mol} \mathrm{L}^{-1}\right)$ & $\mathrm{R}_{\mathrm{ct}}(\Omega)$ & Recovery $(\%)$ \\
\hline \multirow{3}{*}{ Mineral water } & $10^{-5}$ & 817.33 & 96.1 \\
& $10^{-4}$ & 692.1 & 96.9 \\
& $10^{-3}$ & 323.44 & 98.7 \\
Well water & $10^{-5}$ & 989.3 & 95.5 \\
& $10^{-4}$ & 852.5 & 96.3 \\
& $10^{-3}$ & 395.3 & 98.3 \\
\hline
\end{tabular}

good correlation $\left(\mathrm{R}^{2}=0.99\right)$. The sensitivity values were determined as 0.78 and $0.5 \mathrm{~mA} \mathrm{L.mol}{ }^{-1}$ with corresponding limit detection estimated as $5 \mu \mathrm{M}$ and $1.5 \mu \mathrm{M}$ for the IIP and NIP electrode, respectively. These electrochemical performances were better than those obtained using other electrochemical sensors listed in Table 2.

3.10. Reproducibility, Durability, and Interference Study. To study the reproducibility of the sensor, the impedance signal for known nitrate concentration was carried out for 7 independent fabricated imprinted sensors. The relative standard deviation (RSD) of the sensors response to $1 \mathrm{mM}$ nitrate was 3 $\%$, indicating high reproducibility. Furthermore, the sensors were soaked in $0.1 \mathrm{M}$ hydrochloric solution and then tested daily to measure durability. The RSD of the sensors' response to $1.0 \mathrm{mM}$ of nitrate was $5 \%$ during four weeks indicating high durability.

The selectivity of the IIP sensor was obtained by linear sweep voltammetry method in $0.1 \mathrm{mM}$ of $\mathrm{NO}_{3}{ }^{-}$with the addition of various interference ions at fixed concentration of $10 \mathrm{mM}$. The comparison result is summarized in Figure 10. As expected, the determination of $0.1 \mathrm{mM}$ of nitrate is not interfered by the presence of ions such as $\mathrm{NO}_{2}{ }^{-}, \mathrm{Ca}^{2+}, \mathrm{PO}_{4}{ }^{3-}$, $\mathrm{Mg}^{2+}$, and $\mathrm{CO}_{3}{ }^{2-}$ in a 100 -fold concentration; this may be attributed to the complementary cavities in the polymeric matrix which match the unique molecular structure of $\mathrm{NO}_{3}{ }^{-}$ sterically and via multiple interactions between the functional groups in the imprinted matrix and the template.

3.11. Real Analytical Application of the Sensor. The developed electrochemical imprinted sensor was further employed to

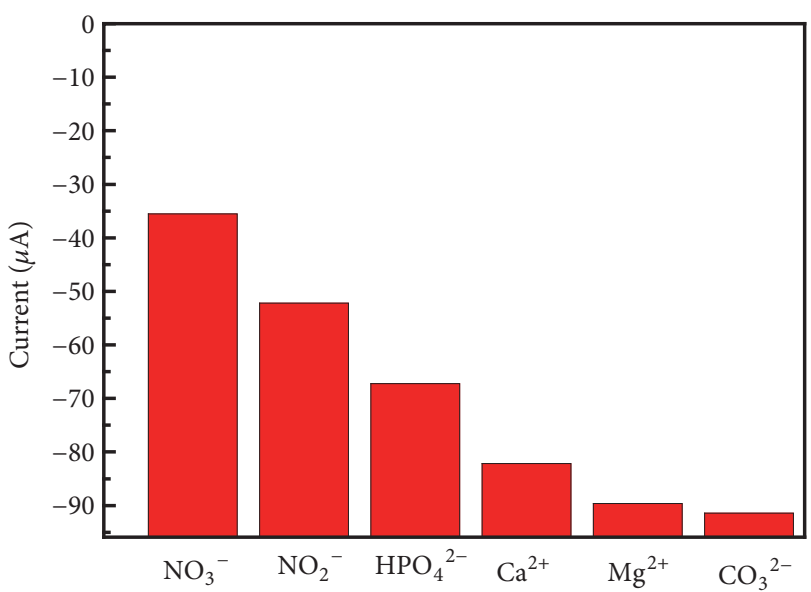

FIGURE 10: Electrochemical interference of IIP-GCE/Cu-NPs/PANI in solutions containing different ions $(\mathrm{pH}=5)$.

detect nitrate in well and mineral water to investigate the feasibility for practical values by performing recovery tests. The response of the sensor was evaluated using the impedance method with the addition of different concentrations of $\mathrm{NO}_{3}{ }^{-}$. It was observed that the $\mathrm{R}_{\mathrm{ct}}$ values increased with the increase of $\mathrm{NO}_{3}{ }^{-}$concentration such as $10^{-5}, 10^{-4}$, and $10^{-3} \mathrm{M}$. The recovery was calculated, and the results are summarized in Table 3. The results show that the imprinted sensor has a good recovery from 95.5 to $98.7 \%$ to detect nitrate ions, which manifests IIP-Cu-NPs/PANI/GCE to be sensitive and a useful tool for nitrate quantification in real samples. 


\section{Conclusions}

In this study, a novel IIP-Cu-NPs/PANI/GCE sensor for selective recognition of $\mathrm{NO}_{3}{ }^{-}$was successfully developed. The sensor matrix was synthesized by electropolymerization of PANI on the $\mathrm{Cu}$-NPs modified GCE surface using cyclic voltammetry technique. And the sensing performances were investigated in optimal conditions by varying the matrix thickness, the $\mathrm{pH}$ value, the scan rate, and the concentrations of monomer and template. Owing to the unique mechanical properties and extremely large area of the $\mathrm{Cu}-\mathrm{NPs}$, the resulting IIP-Cu-NPs/PANI membrane exhibits high sensitivity, good reproducibility, and selectivity. The obtained linear range for nitrate determination is from $1 \mu \mathrm{M}$ to $100 \mathrm{mM}$, and the detection limit is estimated to be $2 \cdot 10^{-7} \mathrm{~mol} \mathrm{~L}^{-1}$ for the NIP and $3,1.10^{-7} \mathrm{~mol} \mathrm{~L}^{-1}$ for the IIP. The results of recovery obtained during the detection of $\mathrm{NO}_{3}{ }^{-}$ions in mineral water and well water confirm that this method is favorable for nitrate detection in real samples. Furthermore, this highly sensitive IIP-Cu-NPs/PANI/GCE based nitrate ion sensor can be used for environmental monitoring thanks to its simplicity, selectivity, and low cost.

\section{Data Availability}

The data used to support the findings of this study are included within the article.

\section{Conflicts of Interest}

The authors declare no conflicts of interest and the mentioned received funding did not lead to any conflicts of interest regarding the publication of this manuscript.

\section{Authors' Contributions}

Houda Essousi, Houcine Barhoumi, and Malek Bibani conceived and designed the experiments and wrote the paper; Nadia Ktari performed and construed the MEB experiments; Frank Wendler, Ammar Al-Hamry, and Olfa Kanoun analyzed the data.

\section{Acknowledgments}

The authors would like to acknowledge PRF-2017-D4P1 Tunisia project (No. 12Mag088) and the Ministry of Higher Education and Scientific Research of Tunisia (LR11ES55).

\section{References}

[1] D. Pan, W. Lu, H. Zhang, L. Zhang, and J. Zhuang, "Voltammetric determination of nitrate in water samples at copper modified bismuth bulk electrode," International Journal of Environmental Analytical Chemistry, vol. 93, no. 9, pp. 935-945, 2013.

[2] W. Ren, S. Mura, and J. M. K. Irudayaraj, "Modified graphene oxide sensors for ultra-sensitive detection of nitrate ions in water," Talanta, vol. 143, pp. 234-239, 2015.

[3] H. Bagheri, A. Hajian, M. Rezaei, and A. Shirzadmehr, "Composite of $\mathrm{Cu}$ metal nanoparticles-multiwall carbon nanotubesreduced graphene oxide as a novel and high performance platform of the electrochemical sensor for simultaneous determination of nitrite and nitrate," Journal of Hazardous Materials, vol. 324, pp. 762-772, 2017.

[4] M. E. Alahi, S. C. Mukhopadhyay, and L. Burkitt, "Imprinted polymer coated impedimetric nitrate sensor for real- time water quality monitoring," Sensors and Actuators B: Chemical, vol. 259, pp. 753-761, 2018.

[5] E. Bomar, G. Owens, and G. Murray, "Nitrate ion selective electrode based on ion imprinted poly(N-methylpyrrole)," Chemosensors, vol. 5, no. 1, p. 2, 2017.

[6] I. H. Tang, R. Sundari, H. O. Lintang, and L. Yuliati, "Detection of nitrite and nitrate ions in water by graphene oxide as a potential fluorescence sensor," aterials Science and Engineering, vol. 107, p. 012027, 2016.

[7] D. Kimshapiro, M. Gladwin, R. Patel, and N. Hogg, "The reaction between nitrite and hemoglobin: the role of nitrite in hemoglobin-mediated hypoxic vasodilation," Journal of Inorganic Biochemistry, vol. 99, no. 1, pp. 237-246, 2005.

[8] J. Liang, Y. Zheng, and Z. Liu, "Nanowire-based Cu electrode as electrochemical sensor for detection of nitrate in water," Sensors and Actuators B: Chemical, vol. 232, pp. 336-344, 2016.

[9] S. M. van Zijderveld, W. J. J. Gerrits, J. A. Apajalahti et al., "Nitrate and sulfate: Effective alternative hydrogen sinks for mitigation of ruminal methane production in sheep," Journal of Dairy Science, vol. 93, no. 12, pp. 5856-5866, 2010.

[10] B. C. Choi, "N-nfrroso compounds and human cancer: a molecular epidemiologic approach," American Journal of Epidemiology, vol. 121, no. 5, pp. 737-743, 1985.

[11] W. L. Daniel, M. S. Han, J.-S. Lee, and C. A. Mirkin, "Colorimetric nitrite and nitrate detection with gold nanoparticle probes and kinetic end points," Journal of the American Chemical Society, vol. 131, no. 18, pp. 6362-6363, 2009.

[12] J. D. Brender, J. M. Olive, M. Felkner, L. Suarez, W. Marckwardt, and K. A. Hendricks, "Dietary nitrites and nitrates, nitrosatable drugs, and neural tube defects," Epidemiology, vol. 15, no. 3, pp. 330-336, 2004.

[13] M. Badea, A. Amine, G. Palleschi, D. Moscone, G. Volpe, and A Curulli, "New electrochemical sensors for nitrites and nitrates," Journal of Electroanalytical Chemistry, vol. 519, pp. 66-72, 2001.

[14] Y. C. Moo, M. Z. Matjafri, H. S. Lim, and C. H. Tan, "New development of optical fiber sensor for determination of nitrate and nitrite in water," Optik - International Journal for Light and Electron Optics, vol. 127, pp. 1312-1319, 2016.

[15] A. Sempere, J. Oliver, and C. Ramos, "Simple determination of nitrate in soils by second-derivative spectroscopy," Soil Science, vol. 44, no. 4, pp. 633-639, 1993.

[16] K. Chon, Y. Lee, J. Traber, and U. Von Gunten, "Quantification and characterization of dissolved organic nitrogen in wastewater effluents by electrodialysis treatment followed by size-exclusion chromatography with nitrogen detection," Water Research, vol. 47, no. 14, pp. 5381-5391, 2013.

[17] M. D. Croitoru, "Nitrite and nitrate can be accurately measured in samples of vegetal and animal origin using an HPLC-UV/VIS technique," Journal of Chromatography B, vol. 911, pp. 154-161, 2012.

[18] K. Kim, K. L. Kim, and K. S. Shin, "Selective detection of aqueous nitrite ions by surface-enhanced Raman scattering of 4-aminobenzenethiol on Au," Analyst, vol. 137, no. 16, pp. 38363840, 2012.

[19] H. Kodamatani, S. Yamazaki, K. Saito, T. Tomiyasu, and Y. Komatsu, "Selective determination method for measurement of 
nitrite and nitrate in water samples using high-performance liquid chromatography with post-column photochemical reaction and chemiluminescence detection," Journal of Chromatography A, vol. 1216, no. 15, pp. 3163-3167, 2009.

[20] J. Davis, M. J. Moorcroft, S. J. Wilkins, R. G. Compton, and M. F. Cardosi, "Electrochemical detection of nitrate and nitrite at a copper modified electrode," Analyst, vol. 125, no. 4, pp. 737-742.

[21] F. Manea, A. Remes, C. Radovan, R. Pode, S. Picken, and J. Schoonman, "Simultaneous electrochemical determination of nitrate and nitrite in aqueous solution using Ag-doped zeoliteexpanded graphite-epoxy electrode," Talanta, vol. 83, no. 1, pp. 66-71, 2010.

[22] M. J. Shiddiky, M. Won, and Y. Shim, "Simultaneous analysis of nitrate and nitrite in a microfluidic device with a $\mathrm{Cu}$-complexmodified electrode," Electrophoresis, vol. 27, no. 22, pp. 45454554, 2006.

[23] Y. Li, H. Li, Y. Song et al., "An electrochemical sensor system with renewable copper nano-clusters modified electrode for continuous nitrate determination," IEEE Sensors Journal, vol. 16, pp. 8807-8814, 2016.

[24] H. Hrichi, L. Monser, and N. Adhoum, "A novel electrochemical sensor based on electropolymerized molecularly imprinted poly(aniline-co-anthranilic acid) for sensitive detection of amlodipine," Journal of Electroanalytical Chemistry, vol. 805, pp. 133-145, 2017.

[25] H. Essousi and H. Barhoumi, "Electroanalytical application of molecular imprinted polyaniline matrix for dapsone determination in real pharmaceutical samples," Journal of Electroanalytical Chemistry, vol. 818, pp. 131-139, 2018.

[26] H. Yan and K. H. Row, "Characteristic and synthetic approach of molecularly imprinted polymer," International Journal of Molecular Sciences, vol. 7, no. 5-6, pp. 155-178, 2006.

[27] S. A. Piletsky and A. P. Turner, "Electrochemical sensors based on molecularly imprinted polymers," Electroanal, vol. 14, pp. 317-323, 2002.

[28] X. Luo, S. Luo, Y. Zhan, H. Shu, Y. Huang, and X. Tu, "Novel $\mathrm{Cu}$ (II) magnetic ion imprinted materials prepared by surface imprinted technique combined with a sol-gel process," Journal of Hazardous Materials, vol. 192, no. 3, pp. 949-955, 2011.

[29] M. Andaç, E. Özyapı, S. Şenel, R. Say, and A. Denizli, "Ionselective imprinted beads for aluminum removal from aqueous solutions," Industrial \& Engineering Chemistry Research, vol. 45, no. 5, pp. 1780-1786, 2006.

[30] M. S. Cho, S. Y. Park, J. Y. Hwang, and H. J. Choi, "Synthesis and electrical properties of polymer composites with polyaniline nanoparticles," Materials Science and Engineering C: Materials for Biological Applications, vol. 24, no. 1-2, pp. 15-18, 2004.

[31] D. Zhang and Y. Wang, "Synthesis and applications of onedimensional nano-structured polyaniline: An overview," Materials Science and Engineering: B, vol. 134, no. 1, pp. 9-19, 2006.

[32] R. Sha, K. Komori, and S. Badhulika, "Graphene-Polyaniline composite based ultra-sensitive electrochemical sensor for nonenzymatic detection of urea," Electrochimica Acta, vol. 233, pp. 44-51, 2017.

[33] B. Liu and B.-X. Zou, "Electrocatalytic sensing of nitrate at $\mathrm{Cu}$ nanosheets electrodeposited on $\mathrm{WO}_{3}$ /polyaniline modified electrode," Advanced Materials Research, vol. 881-883, pp. 159164, 2014.

[34] D. Pletcher and Z. Poorabedi, "The reduction of nitrate at a copper cathode in aqueous acid," Electrochimica Acta, vol. 24, no. 12 , pp. 1253-1256, 1979.
[35] G. E. Dima, G. L. Beltramo, and M. T. M. Koper, "Nitrate reduction on single-crystal platinum electrodes," Electrochimica Acta, vol. 50, no. 21, pp. 4318-4326, 2005.

[36] S. Cattarin, "Electrochemical reduction of nitrogen oxyanions in $1 \mathrm{M}$ sodium hydroxide solutions at silver, copper and CuInSe2 electrodes," Journal of Applied Electrochemistry, vol. 22, no. 11, pp. 1077-1081, 1992.

[37] K. Fajerwerg, V. Ynam, B. Chaudret, V. Garçon, D. Thouron, and M. Comtat, "An original nitrate sensor based on silver nanoparticles electrodeposited on a gold electrode," Electrochemistry Communications, vol. 12, no. 10, pp. 1439-1441, 2010.

[38] J. Yang, J. Chen, Y. Zhou, and K. Wu, "A nano-copper electrochemical sensor for sensitive detection of chemical oxygen demand," Sensors and Actuators B: Chemical, vol. 153, no. 1, pp. 78-82, 2011.

[39] A. Stortini, L. Moretto, A. Mardegan, M. Ongaro, and P. Ugo, "Arrays of copper nanowire electrodes: Preparation, characterization and application as nitrate sensor," Sensors and Actuators B: Chemical, vol. 207, pp. 186-192, 2015.

[40] S. Luanwuthi, A. Krittayavathananon, P. Srimuk, and M. Sawangphruk, "In situ synthesis of permselective zeolitic imidazolate framework-8/graphene oxide composites: Rotating disk electrode and Langmuir adsorption isotherm $\dagger$," RSC Advances, vol. 5, no. 58, pp. 46617-46623, 2015.

[41] V. Gau, S.-C. Ma, H. Wang, J. Tsukuda, J. Kibler, and D. A. Haake, "Electrochemical molecular analysis without nucleic acid amplification," Methods, vol. 37, no. 1, pp. 73-83, 2005.

[42] B. Hafezi and M. R. Majidi, "A sensitive and fast electrochemical sensor based on copper nanostructures for nitrate determination in foodstuffs and mineral waters," Analytical Methods, vol. 5, no. 14, pp. 3552-3556, 2013.

[43] L. Yu, Q. Zhang, Q. Xu et al., "Electrochemical detection of nitrate in $\mathrm{PM}_{2.5}$ with a copper-modified carbon fiber micro-disk electrode," Talanta, vol. 143, pp. 245-253, 2015.

[44] J. C. Gamboa, R. C. Peña, T. R. Paixão, and M. Bertotti, “A renewable copper electrode as an amperometric flow detector for nitrate determination in mineral water and soft drink samples," Talanta, vol. 80, no. 2, pp. 581-585, 2009.

[45] J. Laska, R. Girault, S. Quillard, G. Louarn, A. Proń, and S. Lefrant, "Raman spectroscopic studies of polyaniline protonation with bis(2-ethylhexyl) hydrogen phosphate," Synthetic Metals, vol. 75, no. 1, pp. 69-74, 1995.

[46] M. Wan, "Absorption spectra of thin film of polyaniline," Journal of Polymer Science Part A: Polymer Chemistry, vol. 30, no. 4, pp. 543-549.

[47] L. A. Diaz, A. Valenzuela-Muñiz, M. Muthuvel, and G. G. Botte, "Analysis of ammonia electro-oxidation kinetics using a rotating disk electrode," Electrochimica Acta, vol. 89, pp. 413421, 2013.

[48] I. O. K’Owino and O. A. Sadik, "Impedance spectroscopy: A powerful tool for rapid biomolecular screening and cell culture monitoring," Electroanalysis, vol. 17, no. 23, pp. 2101-2113, 2005.

[49] A. Zamora-Gálvez, A. Ait-Lahcen, L. A. Mercante, E. MoralesNarváez, A. Amine, and A. Merkoçi, "Molecularly imprinted polymer-decorated magnetite nanoparticles for selective sulfonamide detection," Analytical Chemistry, vol. 88, no. 7, pp. 3578-3584, 2016.

[50] Z. Zhang, S. Zhai, M. Wang et al., "Electrochemical sensor based on a polyaniline-modified $\mathrm{SnO}_{2}$ nanocomposite for detecting ethephon," Analytical Methods, vol. 7, no. 11, pp. 4725-4733, 2015. 
[51] Y. Zhang, L. Wu, W. Lei, X. Xia, M. Xia, and Q. Hao, "Electrochemical determination of 4-nitrophenol at polycarbazole/Ndoped graphene modified glassy carbon electrode," Electrochimica Acta, vol. 146, pp. 568-576, 2014.

[52] G.-H. Yao, R.-P. Liang, C.-F. Huang, Y. Wang, and J.-D. Qiu, "Surface plasmon resonance sensor based on magnetic molecularly imprinted polymers amplification for pesticide recognition," Analytical Chemistry, vol. 85, no. 24, pp. 11944-11951, 2013.

[53] A. Bogomolova, E. Komarova, K. Reber et al., "Challenges of electrochemical impedance spectroscopy in protein biosensing," Analytical Chemistry, vol. 81, no. 10, pp. 3944-3949, 2009.

[54] D. A. Gough and J. K. Leypoldt, "Membrane-covered, rotated disk electrode," Analytical Chemistry, vol. 51, no. 3, pp. 439-444, 2002.

[55] H. Barhoumi, A. Maaref, M. Rammah et al., "Insulator semiconductor structures coated with biodegradable latexes as encapsulation matrix for urease," Biosensors and Bioelectronics, vol. 20, no. 11, pp. 2318-2323, 2005.

[56] C. Hsueh and A. Brajter-Toth, "Electrochemical preparation and analytical applications of ultrathin overoxidized polypyrrole films," Analytical Chemistry, vol. 66, no. 15, pp. 2458-2464, 1994.

[57] O. V. Kaminskaya, E. A. Zakharova, and G. B. Slepchenko, "Simultaneous voltammetric determination of nitrites and nitrates in waters," Journal of Analytical Chemistry, vol. 59, no. 11, pp. 1091-1096, 2004. 


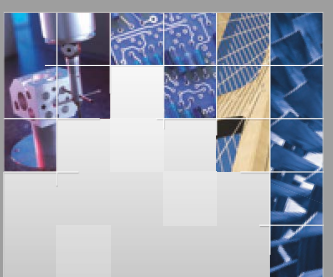

\section{Enfincering}
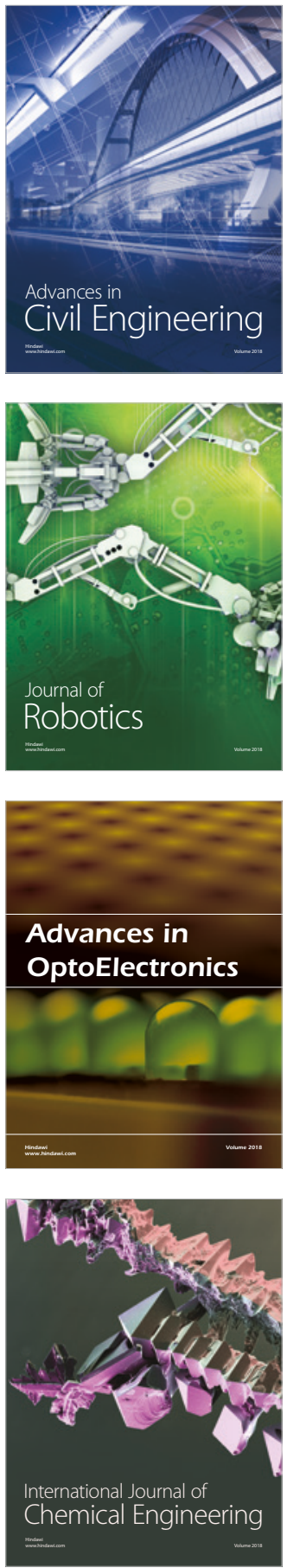

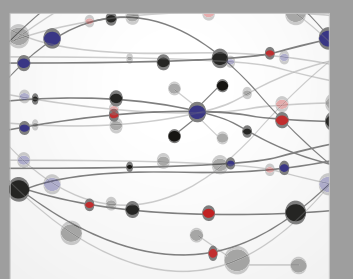

\section{Rotating \\ Machinery}

The Scientific World Journal

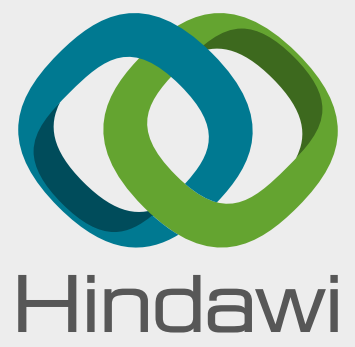

Submit your manuscripts at

www.hindawi.com
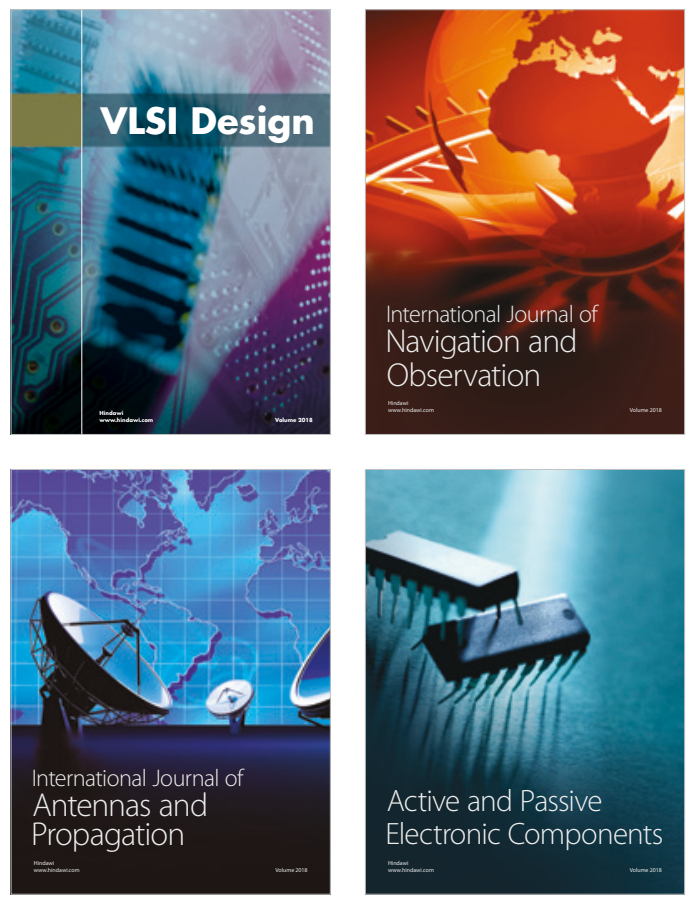
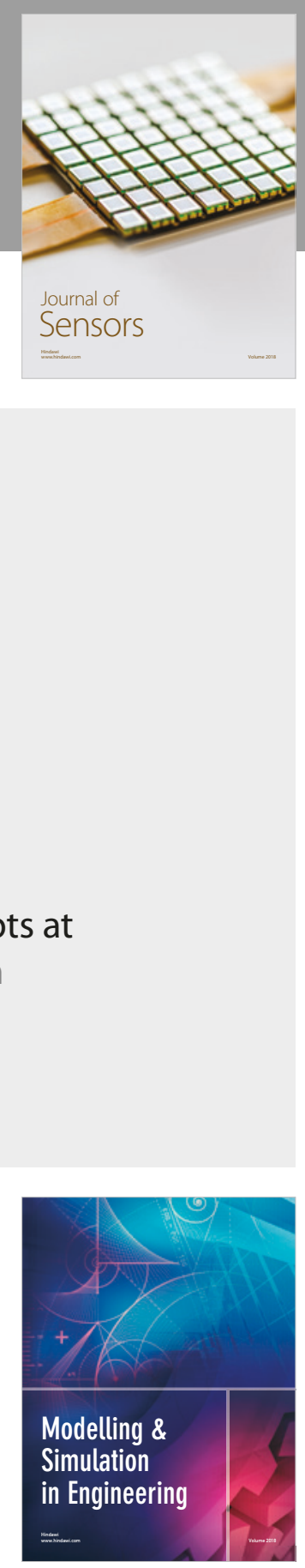

\section{Advances \\ Multimedia}
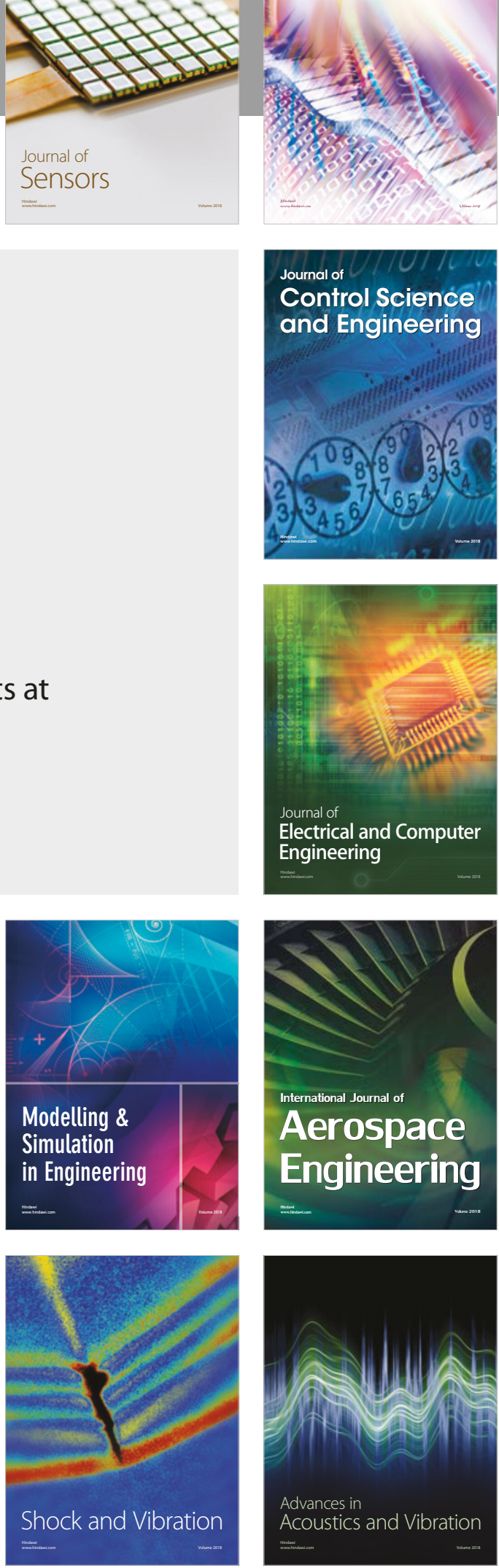